NBER WORKING PAPER SERIES

\title{
A NO-ARBITRAGE VECTOR AUTOREGRESSION OF TERM STRUCTURE DYNAMICS WITH MACROECONOMIC AND LATENT VARIABLES
}

\author{
Andrew Ang \\ Monika Piazzesi \\ Working Paper 8363 \\ http://www.nber.org/papers/w8363 \\ NATIONAL BUREAU OF ECONOMIC RESEARCH \\ 1050 Massachusetts Avenue \\ Cambridge, MA 02138 \\ July 2001
}

We have had helpful discussions with Geert Bekaert, Mike Chernov, John Cochrane, Darrell Duffie, Charles Evans, Mark Ferguson, Bob Hodrick, Avi Kamara, Jun Liu, David Marshall, Jun Pan, Thomas Sargent, Stephen Schaefer, Martin Schneider, Ken Singleton and Suresh Sundaresan. We thank seminar participants at Columbia University, the 2000 NBER Summer Institute, the 2000 Western Finance Association meetings and the Seventh World Congress of the Econometric Society. The views expressed herein are those of the authors and not necessarily those of the National Bureau of Economic Research.

(C) 2001 by Andrew Ang and Monika Piazzesi. All rights reserved. Short sections of text, not to exceed two paragraphs, may be quoted without explicit permission provided that full credit, including $\mathbb{C}$ notice, is given to the source. 
A No-Arbitrage Vector Autoregression of Term Structure Dynamics

with Macroeconomic and Latent Variables

Andrew Ang and Monika Piazzesi

NBER Working Paper No. 8363

July 2001

JEL No. E4, E5, G0

\begin{abstract}
$\underline{\text { ABSTRACT }}$
This paper describes the joint dynamics of bond yields and macroeconomic variables in a Vector Autoregression, where identifying restrictions are based on the absence of arbitrage. Using a term structure model with inflation and economic growth factors, we investigate how macro variables affect bond prices and the dynamics of the yield curve. The setup accommodates higher order autoregressive lags for the macro factors. The macro variables are augmented by traditional unobserved term structure factors. We find that the forecasting performance of a VAR improves when no-arbitrage restrictions are imposed. Models that incorporate macro factors forecast better than traditional term structure models with only unobservable factors. Variance decompositions show that macro factors explain up to $85 \%$ of the variation in bond yields. Macro factors primarily explain movements at the short end and middle of the yield curve while unobservable factors still account for most of the movement at the long end of the yield curve.
\end{abstract}

Andrew Ang

Columbia Business School

3022 Broadway

805 Uris

New York, NY 10027

and NBER

Tel: 212-854-9154

Fax: 212-662-8474

aa610@,columbia.edu

http://www.columbia.edu/ aa610
Monika Piazzesi

Anderson Graduate School of Management

UCLA

110 Westwood Plaza, Box 951481

Los Angeles, CA 90095-1481

and NBER

Tel: $310-825-3544$

Fax: 310-725-5702

piazzesi@ucla.edu

http://www.personal.anderson.ucla.edu/monika.piazzesi 


\section{Introduction}

Describing the joint behavior of the yield curve and macroeconomic variables is important for bond pricing, investment decisions and public policy. Many term structure models have used latent factor models to explain term structure movements, and although there are some interpretations to what these factors mean, the factors are not given direct comparisons with macroeconomic variables. For example, Pearson and Sun (1994)'s factors are labeled "short rate" and "inflation", but their estimation does not use inflation data. The terms "short rate" and "inflation" are just convenient names for the unobserved factors. Another example is Knez, Litterman and Scheinkman (1994), who call their factors "level," "slope" and "curvature". Similarly, Dai and Singleton (2000) use the words "level," "slope" and "butterfly" to describe their factors. These labels stand for the effect the factors have on the yield curve rather than describing the economic sources of the shocks.

In the absence of a workhorse general equilibrium model for asset pricing (see Hansen and Jagannathan (1991)), factor models have the advantage that they only impose no-arbitrage conditions and not all other conditions that characterize the equilibrium in the economy. Most existing factor models of term structure are unsatisfactory, however, because they do not model how yields directly respond to macroeconomic variables. ${ }^{1}$ In contrast, empirical studies try to directly model the relationships between bond yields and macro variables by using Vector Autoregressive (VAR) models. Studies like Estrella and Mishkin (1997) and Evans and Marshall (1998) use VAR's with yields of various maturities together with macro variables. Using the VAR, these studies infer the relationships between yield movements and shocks in macro variables using impulse responses (IR's) and variance decomposition techniques. For example, Evans and Marshall (2000) associate shocks to economic activity and price levels with level effects across the yield curve. Another type of shock which can be identified with various schemes comes from monetary policy (see, for example, Gali (1992), Sims and Zha (1995), Bernanke and Mihov (1995), Christiano, Eichenbaum and Evans (1996a), and Uhlig (1999). For a survey, see Christiano, Eichenbaum and Evans (1998)).

Existing macro VAR studies are characterized by three features. First, only maturities whose yields which have been included in the VAR may have their behavior directly inferred by the dynamics of the VAR. As an unrestricted VAR is generally not a complete theory of the term structure, it says little about how yields of maturities not included in the VAR may move. Second, the implied movements of yields in relation to each other may not rule out arbitrage opportunities when the cross-equation restrictions implied by this assumption are not imposed in the estimation. Finally, unobservable variables cannot be included as all variables in the VAR must

\footnotetext{
${ }^{1}$ The exception is Piazzesi (2001), who uses a term structure model with interest-rate targeting by the central bank and releases of macroeconomic variables such as nonfarm payroll employment.
} 
be observable. The VAR approach, however, is very flexible, and the Impulse Response Functions (IR's) and variance decompositions give insights into the relationships between macro shocks and movements in the yield curve.

A related asset-pricing literature beginning with Sargent (1979) has tried to estimate VAR systems of yields under the null of the Expectations Hypothesis (see Bekaert and Hodrick (2001)). While the validity of the Expectations Hypothesis as a term structure model is still being debated (see Fisher and Gilles (1998) and Longstaff (2000)), this literature has not focused on incorporating macro variables into the VAR. Our approach in this paper specifically focuses on how macro variables affect term structure dynamics, where the term structure dynamics are given by a Gaussian (VAR) term structure model with time-varying risk premia, consistent with deviations from the Expectations Hypothesis (see Fisher (1998) and Dai and Singleton (2001)).

We incorporate macro variables as factors in a term structure model by using a factor representation for the pricing kernel, which prices all bonds in the economy. The pricing kernel depends on the shocks to both observed macro factors and unobserved factors. Since macro factors are correlated with yields, incorporating these factors may lead to models whose forecasts are better than models which omit these factors. We investigate whether the purely unobservable factors of multi-factor term structure models can be explained by macro variables, and we examine how the latent factors change when macro variables are incorporated into such models. Using a pricing kernel with macro factors is a direct and tractable way of modeling how macro factors affect bond prices.

Our methodology gives us several advantages over existing empirical VAR approaches. First, it allows us to characterize the behavior of the entire yield curve in response to macro shocks rather than just the yields included in the VAR. Second, a direct comparison of macro variables with latent yield factors can be made. Third, variance decompositions and other methods can estimate the proportion of term structure movements attributable to observable macro shocks, and other latent variables. Finally, our approach retains the tractability of the VAR approaches because we estimate a VAR subject to nonlinear no-arbitrage restrictions.

The model is a discrete-time multi-factor model with time-varying risk premia. This term structure model is Gaussian, like a VAR model, and IR's and variance decompositions from the model can be easily obtained. Formally, our model is a special case of discrete-time versions of the affine class introduced by Duffie and Kan (1996), where bond prices are exponential affine functions of underlying state variables. In our model, however, some of the state variables are observed macroeconomic aggregates. With Gaussian processes, the affine model reduces to a VAR with cross-equation restrictions. Our set-up accommodates lags and moving average 
errors in the driving factors and allows us to compute variance decompositions where we can attribute the proportion of movements in the yield curve to observable and unobservable factors. We can plot IR's of shocks to various factors on any yield, since the no-arbitrage model gives us bond prices for all maturities.

Our measures of inflation and real activity are obtained from extracting principal components of two groups of variables that are selected to represent measures of price changes and economic growth. These factors are then augmented by latent variables. As term structure studies have suggested up to three latent factors as appropriate to capture most salient features of the yield curve, we estimate models with three latent factors in addition to the macro variables. Our main model has three correlated unobservable factors, together with the two macro factors (inflation and real economic activity).

The cross-equation restrictions from no arbitrage improve out-of-sample forecasts from a VAR. We find that these forecasts can be further improved by incorporating macro factors into models with latent variables. We show that a significant part of the latent factors implied by traditional models with only latent yield variables can be attributed to macro variables. In particular, "slope" and "curvature" factors can be related to macro factors, while the "level" factor survives largely intact when macro variables are incorporated.

We find that macro factors explain a significant amount of the variation in bond yields. Macro factors explain up to $85 \%$ of the forecast variance at long horizons at short and medium maturities of the yield curve. The proportion of forecast variance of yields attributable to macro factors decreases at longer yields. At the long end of the yield curve $60 \%$ of the forecast variance is attributable to macro factors at a 1-month forecast horizon, while at very long forecast horizons over $60 \%$ of the variance is attributable to unobservable factors.

This paper is organized as follows. Section 2 summarizes the data and details the construction of the macro factors as principal components of several macroeconomic variables. Section 3 motivates an affine equation for the short rate, which can be interpreted as a regression of the short rate on macro factors and an 'unexplained' component of short rate movements. This last term consists of one or more unobservable (orthogonal) factors. If the latent component is orthogonal to the macro variables, we can interpret this regression as versions of a Taylor (1993) rule, where the short rate responds to a linear combination of observable factors, and an orthogonal unobserved component. Section 4 presents the general model, discusses the estimation strategy, and describes the specific parameterization of the model to be estimated. We lay out our estimation results in Section 5, and discuss the implied IR's, variance decompositions and forecasting results. Section 6 concludes. 


\section{Data}

\subsection{Yield Data}

We use data on zero coupon bond yields of maturities 1, 3, 12, 36 and 60 months from January 1952 to December 2000. The bond yields (12, 36 and 60 months) are from the Fama CRSP zero coupon files, while the shorter maturity rates (1 and 3 months) are from the Fama CRSP Treasury Bill files. Figure 1 plots some of these yields in the upper graph and Table 1 presents some sample statistics. The table shows that the data are characterized by some standard stylized facts. The average postwar yield curve is upward sloping; standard deviations of yields generally decrease with maturity; and yields are highly autocorrelated, with increasing autocorrelation at longer maturities.

The yield levels show mild excess kurtosis at short maturities which decreases with maturity, and significantly positive skewness at all maturities. Excess kurtosis is, however, more pronounced for first-differenced yields (for example, 19.44 for the 1-month yield). Although the distribution of yields in the 1990's seems to exhibit Gaussian tails, the evidence for the long series of monthly postwar yields rejects a normal distribution. For our purposes, the Gaussian assumption made in later sections is a sufficient first approximation to the dynamics of the yield curve, as we are mainly interested in the joint dynamics of yields and macroeconomic variables. The Gaussian model we present in Section 4 can be extended to incorporate heteroskedastic dynamics parameterized by discretized square-root processes.

An important stylized fact is that yields of near maturity are extremely correlated - the correlation between the 36-month and 60-month yield is 99\%. In our estimations we use all five yields to estimate our models, but we specify that some of the yields are measured with error. We choose the 1, 12 and 60-month yields to be measured without error to represent the short, medium and long ends of the yield curve in our models with 3 unknown factors. (The 3 -month yield has a 99\% correlation with the 12-month yield, and the 36-month yield has a $99 \%$ correlation with the 60 -month yield.)

\subsection{Macro Variables}

We use macro variables that can be sorted in two groups. The first group consists of various inflation measures which are based on the CPI, the PPI of finished goods, and spot market commodity prices (PCOM). The second group contains variables that capture real activity: the index of Help Wanted Advertising in Newspapers (HELP), unemployment (UE), the growth rate of employment (EMPLOY) and the growth rate of industrial production (IP). This list of variables includes most variables that have been used in monthly VAR's in the macro literature. 
Among these variables, PCOM and HELP are traditionally thought of as leading indicators of inflation and real activity, respectively. All growth rates (including inflation) are measured as the difference in logs of the index at time $t$ and $t-12, t$ in months.

To reduce the dimensionality of the system, we extract the first principal component of each group of variables separately. That is, we extract the first principal component from the inflation measures group, and we extract the first principal component from the real activity measures group. This leaves us with two variables which we call "inflation" and "real activity". More precisely, we first normalize the three (four) macro variables related to inflation (real activity) to zero mean and unit variance. For each group, the normalized variable vector $Z_{t}$ can be represented as

$$
Z_{t}=C f_{t}^{o}+\epsilon_{t}
$$

where $Z_{t}=\left(\mathrm{CPI}_{t} \mathrm{PPI}_{t} \mathrm{PCOM}_{t}\right)$ for the inflation group or $Z_{t}=\left(\mathrm{HELP}_{t} \mathrm{UE}_{t} \mathrm{EMPLOY}_{t} \mathrm{IP}_{t}\right)$ for the real activity group. The error term $\epsilon_{t}$ satisfies $\mathrm{E}\left(\epsilon_{t}\right)=0$ and $\operatorname{cov}\left(\epsilon_{t}\right)=\Gamma$, where $\Gamma$ is diagonal. The matrices $C$ and $\Gamma$ are either $3 \times 1$ or $4 \times 1$ for the inflation group and the real activity group respectively. The extracted macro factor $f_{t}^{o}$ has mean zero $\left(\mathrm{E}\left(f_{t}^{o}\right)=0\right)$ and unit $\operatorname{variance}\left(\operatorname{var}\left(f_{t}^{o}\right)=1\right)$.

Table 2 shows the loadings of the first three (four) principal components, and the factor loadings for using only one principal component to explain the variation in each group. Over $70 \%(50 \%)$ of the variance of nominal variables (real variables) is explained by just the first principal component of the group. The first principal component of the inflation measures loads negatively on CPI, PPI, and PCOM. Since negative shocks to this variable represent positive shocks to inflation, we multiply it by -1 so that we can interpret it as an "inflation" factor. The first principal component of real activity measures loads negatively on HELP, EMPLOY, and IP and positively on UE. Again, we multiply this variable by -1 to interpret positive shocks to this factor as positive shocks to economic growth. We call this factor "real activity". We plot these macro factors in the bottom plot in Figure 1.

To obtain some intuition about these constructed measures of inflation and real activity, Figure 2 plots the inflation and real activity measures versus the actual inflation and real activity series. The top plot of Figure 2 graphs the inflation factor in circles versus the normalized inflation measures CPI, PCOM and PPI. The inflation factor closely tracks CPI and PPI, which roughly move together. The bottom plot of Figure 2 graphs the real activity factor in circles versus the economic growth variables HELP, EMPLOY, IP and the negative of UE. All these series have roughly the same cycles, and the real activity factor most closely corresponds with EMPLOY. 
Table 3 displays the correlation between the principal components and the original macro series in each group. These correlations show that the inflation factor is most closely correlated with PPI and CPI (97\% and 93\% respectively) and less correlated with commodity prices (59\%). The real activity factor is most closely correlated with employment growth (91\%) and industrial production $(87 \%)$.

The unconditional correlation between the two macro factors is tiny, one tenth of $1 \%$, as reported in Table 3. Although the unconditional correlation is weak, the lower plot in Figure 1 of the macro factors indicates that some conditional correlations might be important. In fact, when we estimate a VAR for the macro factors, some of the conditional correlations turn out to be significant (they are not reported here). More specifically, we estimate a bivariate process with 12 autoregressive lags for the macro factors:

$$
f_{t}^{o}=\rho_{1} f_{t-1}^{o}+\ldots+\rho_{12} f_{t-12}^{o}+\Omega u_{t-1}
$$

where $\rho_{1}$ to $\rho_{12}$ and $\Omega$ are $2 \times 2$ matrices with $u_{t}$ IID N(0,I). The estimation results show that the coefficient on the seventh lag of real activity in the inflation equation is significant and the coefficient on the first two lags of inflation in the equation for real activity are significant. This can also be seen from the impulse responses plotted in Figure 3. The response of inflation to shocks in real activity is positive and hump-shaped, while the response of real activity to inflation shocks is initially weakly positive, and then turns slightly negative before dying out. Since principal components are linear transformations of the data, the skewness, kurtosis and autocorrelation of the macro variables (Table 1) are inherited by the principal components $f_{t}^{o}$.

Some preliminary information about the relationship between the macro factors and the yield curve can be gained from the correlation matrix in Table 3. The inflation factor is highly correlated with yields. This correlation is highest for short yields (67\% correlation between inflation and 1-month yields), and somewhat smaller for long yields (56\% correlation between inflation and 60-month yields). Real activity is only weakly correlated with yields. This correlation does not exceed $6 \%$ for any maturity. This weak relationship is not representative for all measures of real activity. For example, the correlation of HELP and 1-month yields is $63 \%$, but our real activity factor loads mostly on EMPLOY and IP. Hence, at least for measures of economic activity, it may matter whether the particular variable in question is a leading indicator of business cycles. This implies that in our analysis we may potentially understate the impact of real activity on the yield curve by the construction of our real activity factor. 


\section{A First Look at Short Rate Dynamics}

\subsection{Policy Rules and Short Rate Dynamics in Affine Models}

According to the policy rule recommended by Taylor (1993), movements in the short rate should be traced to movements in contemporaneous macro variables $f_{t}^{o}$ and a component which is not explained by macro variables, an orthogonal shock $v_{t}$ :

$$
r_{t}=a_{0}+a_{1}^{\prime} f_{t}^{o}+v_{t}
$$

The shock $v_{t}$ may be interpreted as a monetary policy shock following identifying assumptions made in Christiano, Eichenbaum and Evans (1996a,1996b). Taylor's original specification uses two macro variables as factors in $f_{t}^{o}$. The first variable is an annual inflation rate, similar to our inflation factor, and the second variable is the output gap. GDP data are only available at a quarterly frequency, while our real activity factor is constructed using various monthly series such as EMPLOY and IP.

Another type of policy rule that has been proposed by Clarida, Gali, and Gertler (2000) is a forward-looking version of the Taylor rule. According to this rule, the central bank reacts to expected inflation and the expected output gap. This implies that any variable that forecasts inflation or output will enter the right-hand side of (3). In the hope of capturing the information underlying macro forecasts, we add lagged macro variables as arguments in equation (3). ${ }^{2}$ This is done by writing $X_{t}^{o}=\left(f_{t}^{o^{\prime}} f_{t-1}^{o^{\prime}} \ldots, f_{t-p-1}^{o^{\prime}}\right)^{\prime}$ for some lag length $p$ and including the lags as arguments in the policy rule:

$$
r_{t}=b_{0}+b_{1}^{\prime} X_{t}^{o}+v_{t}
$$

Affine term structure models (Duffie and Kan (1996)) are based on a short rate equation just like equation (3) together with an assumption on risk premia. The difference between the short rate dynamics in affine term structure models and the Taylor rule is that in affine term structure models the short rate is specified to be an affine (constant plus linear term) function of underlying latent factors $X_{t}^{u}$ :

$$
r_{t}=c_{0}+c_{1}^{\prime} X_{t}^{u}
$$

\footnotetext{
${ }^{2}$ Clarida, Gali, and Gertler (2000) implement their forward-looking rule by redefining the shock term $v_{t}$ to include forecast errors $f_{t+1}^{o}-\mathrm{E}_{t}\left(f_{t+1}^{o}\right)$. This allows them to use future values of macro variables $f_{t+1}^{o}$ as arguments on the right-hand side of (3). We could in principle adopt the same approach by including these forecast errors into some latent variables, but this would mean that we would have to drop the assumption that latent and macro variables are orthogonal. Our focus is assigning as much explanatory power to macro factors as possible, so we specify the latent variables as orthogonal.
} 
The unobserved factors themselves follow affine processes, of which a VAR is a special Gaussian case. The prices of bonds of longer maturities are explicit exponential affine functions (dependent upon parameters) of $f_{t}^{u}$ if pricing is risk neutral. In the more general case that we consider, the risk adjustment needs to be specified carefully to obtain similar closed-form solutions for bond yields (this is explained in the next section). With or without risk adjustment, equation (5) is always an important determinant of the shape of the entire yield curve in affine term structure models.

Equations (3) through (5) are very similar: they all specify the short rate as affine functions of factors. We can combine them by writing:

$$
r_{t}=\delta_{0}+\delta_{11}^{\prime} X_{t}^{o}+\delta_{12}^{\prime} X_{t}^{u}
$$

The approach we take in this paper is to specify the latent factors $X_{t}^{u}$ as orthogonal to the macro factors $X_{t}^{o}$. In this case, the short rate dynamics of the term structure model can be interpreted

as a version of the Taylor rule with the errors $v_{t}=\delta_{12}^{\prime} X_{t}^{u}$ being unobserved factors. We use the restrictions from no-arbitrage to separately identify the individual unobserved factors.

\subsection{Estimating the Short Rate Dynamics}

The short rate equation (6) can be estimated by ordinary least squares because of the independence assumption on $X_{t}^{o}$ and $X_{t}^{u}$. Table 4 reports the estimation results from two regressions: the original Taylor rule (3) and the forward-looking version of the Taylor rule (4), which incorporates lags of the macro variables. These regression results give a preliminary view as to how much of the yield movements macro factors may explain with respect to the unobservable variables. The $R^{2}$ of the estimated Taylor rule is $45 \%$, while the estimated forward-looking version of the Taylor raises the $R^{2}$ to $53 \%$. These numbers suggest that macro factors should have explanatory power for yield curve movements.

The behavior of the residuals, however, provides some intuition about what to expect from a model with unobservable factors. First, the residuals from both versions of the Taylor rule are highly autocorrelated. The autocorrelation of residuals from the short rate equation with only contemporaneous macro factors is 0.945 , while the autocorrelation from the equation that includes lagged macro factors is slightly lower, 0.937 . The short rate itself has an autocorrelation of 0.972 , indicating that macro variables do explain some of the persistent shocks to the short rate. Second, unless a variable which mimics the short rate itself is placed on the RHS of equation (3), the residuals will follow the same broad pattern as the short rate. This can be seen from Figure 4, which plots the residuals together with the de-meaned short rate. This suggests that the "level" factor found by earliest term structure studies (see Vasicek (1977)), may still 
reappear when macro variables are added in a linear form to the short rate in a term structure model.

The coefficients on inflation and real activity in the simple Taylor rule are both significant and positive. This is consistent with previous estimates of the Taylor rule in the literature, and also the parameter values proposed by Taylor (1993)'s original specification. However, these coefficients are highly sensitive to the sample period selected. In particular, the sign of the Taylor-rule coefficient on real activity crucially depends on the inclusion of the two recessions in 1954 and 1958. This is evident from the plots of real activity and the 1-month yield in Figure 1. There are two major reductions in output around May 1954 and April 1958, which also correspond to NBER recessions. Both these recessions go hand in hand with decreases in the 1-month rate. These two recessions make the Taylor rule coefficient on output positive. If we start the estimation of the Taylor rule later, say in 1960 or 1970, the coefficient on real activity is negative. Only if we start the estimation after the monetary experiment of 1982 is the coefficient positive. Interestingly enough, the coefficient on output is not significant for the whole post-1982 period, but it is significant for the Greenspan years (post-1987). In contrast, Table 4 reports that most parameter estimates for the forward-looking version of the Taylor rule are not significant, except for the 11th lag on the inflation rate and current real activity. This suggests that using many lags in the Taylor rule may lead to an over-parameterized and potentially poorly behaved system.

\section{A Term Structure Model with Macro Factors}

Based on the macro dynamics (2) and the short rate equation (6), we now develop a discretetime term structure model. The model combines observable macroeconomic variables with unobservable or latent factors. Risk premia in our set-up are time-varying, because they are taken to be affine in potentially all of the underlying factors. Section 4.1 presents the general model and Section 4.2 parameterizes the latent variables and risk premia. We outline our estimation procedure in Section 4.3. Section 4.4 summarizes our parameterization.

\subsection{General Setup}

\subsubsection{State Dynamics}

Suppose there are $K_{1}$ observable macro variables $f_{t}^{o}$ and $K_{2}$ latent variables $f_{t}^{u}$. The vector $F_{t}=\left(f_{t}^{o^{\prime}}, f_{t}^{u^{\prime}}\right)^{\prime}$ is assumed to follow a $\operatorname{Gaussian} \operatorname{VAR}(p)$ process:

$$
F_{t}=\Phi_{0}+\Phi_{1} F_{t-1}+\ldots+\Phi_{p} F_{t-p}+\theta_{0} u_{t}
$$


with $u_{t} \sim \operatorname{IID} N(0, I)$. The state of the economy is described by a $K$ vector of state variables $X_{t}$. We partition the state vector $X_{t}$ into observable variables $X_{t}^{o}$ and unobservable variables $X_{t}^{u}$. The observable vector contains current and past levels of macroeconomic variables $X_{t}^{o}=\left(f_{t}^{o^{\prime}} f_{t-1}^{o^{\prime}} \ldots, f_{t-p}^{o^{\prime}}\right)^{\prime}$, while $X_{t}^{u}=f_{t}^{u}$ contains latent yield factors. We take the bivariate $\operatorname{VAR}(12)$ in equation (2) as the process for inflation and real activity so set $p=12$. Moving average terms can be accommodated by including $q$ lagged error terms $\theta_{1} u_{t-1}, \ldots, \theta_{q} u_{t-q}$ on the right hand side of (7). In this case, the vector of observable state variables also includes past innovations to the macro variables $X_{t}^{o}=\left(f_{t}^{o^{\prime}} f_{t-1}^{o^{\prime}} \ldots, f_{t-p}^{o^{\prime}} u_{t-1}^{o^{\prime}} \ldots u_{t-q}^{o^{\prime}}\right)^{\prime}{ }^{3}$

We write the dynamics of $X_{t}=\left(\left(X_{t}^{o}\right)^{\prime}\left(X_{t}^{u}\right)^{\prime}\right)^{\prime}$ in compact form as a first order Gaussian VAR:

$$
X_{t}=\mu+\Phi X_{t-1}+\Sigma \epsilon_{t}
$$

with $\epsilon_{t}=\left(u_{t}^{\prime} 0 \ldots 0\right)^{\prime}$. In the first order companion form, there are blocks of zeros in the $K \times K$ matrix $\Sigma$ to accommodate higher order lags in $F_{t}$.

\subsubsection{Short Rate Equation}

The one-period short rate $r_{t}$ is assumed to be an affine function of all state variables:

$$
r_{t}=\delta_{0}+\delta_{1}^{\prime} X_{t}
$$

We work with monthly data, so that we can use the one-month yield $y_{t}^{1}$ as an observable short rate $r_{t}$. By constraining the coefficient $\delta_{1}$ to depend only on contemporaneous factor values, we can obtain strict versions of the Taylor rule (3). We call this the "Macro Model." We also consider the case where $\delta_{1}$ is unconstrained, which correspond to the forward-looking Taylor rule incorporating lags. We refer to this formulation as the "Macro Lag Model," because it uses lags of macro variables in the short rate equation.

Structural changes (or regime shifts) in the economy may cause the relationships in the factor dynamics (8) and the short rate equation (9) to change over time (Ang and Bekaert (1998)). We will assume that during our sample period, these relationships are stable, just as in Gali (1992), Christiano, Eichenbaum and Evans (1996a) and Cochrane (1998).

\subsubsection{Pricing Kernel}

To develop the term structure model, we use the assumption of no-arbitrage (Harrison and Kreps (1979)) to guarantee the existence of an equivalent martingale measure (or risk-neutral measure) $Q$ such that the price of any asset $V_{t}$ that does not pay any dividends at time $t+1$ satisfies $V_{t}=$

\footnotetext{
${ }^{3}$ In the case of one lag $p=1$ and no MA components $q=0$, then $K=K_{1}+K_{2}$.
} 
$\mathrm{E}_{t}^{Q}\left(\exp \left(-r_{t}\right) V_{t+1}\right)$, where the expectation is taken under the measure $Q$. The Radon-Nikodym derivative (which converts the risk-neutral measure to the data-generating measure) is denoted by $\xi_{t+1}$. Thus, for any $t+1$ random variable $Z_{t+1}$ we have that $\mathrm{E}_{\mathrm{t}}^{\mathrm{Q}}\left(\mathrm{Z}_{\mathrm{t}+1}\right)=\mathrm{E}_{\mathrm{t}}\left(\xi_{\mathrm{t}+1} \mathrm{Z}_{\mathrm{t}+1}\right) / \xi_{\mathrm{t}}$. The assumption of no-arbitrage, or equivalently the assumption of the existence of $\xi_{t+1}$, allows us to price any asset in the economy, in particular all nominal bond prices.

Assume that $\xi_{t+1}$ follows the log-normal process:

$$
\xi_{t+1}=\xi_{t} \exp \left(-\frac{1}{2} \lambda_{t}^{\prime} \lambda_{t}-\lambda_{t}^{\prime} \epsilon_{t+1}\right)
$$

where $\lambda_{t}$ are the time-varying the market prices of risk associated with the sources of uncertainty $\epsilon_{t}$. We parameterize $\lambda_{t}$ as an affine process:

$$
\lambda_{t}=\lambda_{0}+\lambda_{1} X_{t}
$$

for a $K$-dimensional vector $\lambda_{0}$ and a $K \times K$ matrix $\lambda_{1}$. This specification has been used by Constantinides (1992), El Karoui, Myneni and Viswanathan (1992), and Liu (1999), among many others. Fisher (1998) and Dai and Singleton (2001) argue that this specification can explain deviations from the Expectations Hypothesis. Equations (10) and (11) relate shocks in the underlying state variables (macro and latent factors) to $\xi_{t+1}$ and therefore determine how factor shocks affect all yields.

We define the pricing kernel $m_{t+1}$ as:

$$
m_{t+1}=\exp \left(-r_{t}\right) \xi_{t+1} / \xi_{t}
$$

Substituting $r_{t}=\delta_{0}+\delta_{1}^{\prime} X_{t}$ we have:

$$
m_{t+1}=\exp \left(-\frac{1}{2} \lambda_{t}^{\prime} \lambda_{t}-\delta_{0}-\delta_{1}^{\prime} X_{t}-\lambda_{t}^{\prime} \epsilon_{t+1}\right)
$$

\subsubsection{Bond Prices}

We take equation (13) to be a nominal pricing kernel which prices all nominal assets in the economy. This means that the total gross return process $R_{t+1}$ of any nominal asset satisfies:

$$
\mathrm{E}_{t}\left(m_{t+1} R_{t+1}\right)=1
$$

If $p_{t}^{n}$ represents the price of an $n$-period zero coupon bond, then equation (14) allows bond prices to be computed recursively by:

$$
p_{t}^{n+1}=\mathrm{E}_{t}\left(m_{t+1} p_{t+1}^{n}\right)
$$


The state dynamics of $X_{t}$ (equation (8)) together with the dynamics of the short rate $r_{t}$ (equation (9)) and the Radon-Nikodym derivative (equation (10)) form a discrete-time Gaussian $K$-factor model with $K_{1}$ observable factors and $K_{2}$ unobservable factors. It falls within the affine class of term structure models because bond prices are exponential affine functions of the state variables. More precisely, bond prices are given by:

$$
p_{t}^{n}=\exp \left(\bar{A}_{n}+\bar{B}_{n}^{\prime} X_{t}\right)
$$

where the coefficients $\bar{A}_{n}$ and $\bar{B}_{n}$ follow the difference equations:

$$
\begin{aligned}
& \bar{A}_{n+1}=\bar{A}_{n}+\bar{B}_{n}^{\prime}\left(\mu-\Sigma^{\prime} \lambda_{0}\right)+\frac{1}{2} \bar{B}_{n}^{\prime} \Sigma \Sigma^{\prime} \bar{B}_{n}-\delta_{0} \\
& \bar{B}_{n+1}^{\prime}=\bar{B}_{n}^{\prime}\left(\phi-\Sigma \lambda_{1}\right)-\delta_{1}^{\prime}
\end{aligned}
$$

with $\bar{A}_{1}=-\delta_{0}$ and $\bar{B}_{1}=-\delta_{1}$.

These difference equations can be derived by induction using equation (15). ${ }^{4}$ For a oneperiod bond, $n=1$, we have:

$$
\begin{aligned}
p_{t}^{1} & =\mathrm{E}_{t}\left[m_{t+1}\right]=\exp \left\{-r_{t}\right\} \\
& =\exp \left\{-\delta_{0}-\delta_{1}^{\prime} X_{t}\right\} .
\end{aligned}
$$

Matching coefficients leads to $\bar{A}_{1}=-\delta_{0}$ and $\bar{B}_{1}=-\delta_{1}$. Suppose that the price of an $n$-period bond is given by $p_{t}^{n}=\exp \left(A_{n}+B_{n} X_{t}\right)$. Now we show that the exponential form also applies to the price of the $n$ period bond:

$$
\begin{aligned}
p_{t}^{n+1} & =\mathrm{E}_{t}\left[m_{t+1} p_{t}^{n}\right] \\
& =\exp \left\{-r_{t}-\frac{1}{2} \lambda_{t}^{\prime} \lambda_{t}+A_{n}\right\} \mathrm{E}_{t}\left[\exp \left\{-\lambda_{t}^{\prime} \epsilon_{t+1}+B_{n}^{\prime} X_{t+1}\right\}\right] \\
& =\exp \left\{-r_{t}-\frac{1}{2} \lambda_{t}^{\prime} \lambda_{t}+A_{n}\right\} \mathrm{E}_{t}\left[\exp \left\{-\lambda_{t}^{\prime} \epsilon_{t+1}+B_{n}^{\prime}\left(\mu+\phi X_{t}+\Sigma \epsilon_{t+1}\right)\right\}\right] \\
& =\exp \left\{A_{n}-\delta_{0}+B_{n}^{\prime} \mu+\left(B_{n}^{\prime} \phi-\delta_{1}^{\prime}\right) X_{t}-\frac{1}{2} \lambda_{t}^{\prime} \lambda_{t}\right\} \mathrm{E}_{t}\left[\exp \left\{-\left(\lambda_{t}^{\prime}+B_{n}^{\prime} \Sigma\right) \epsilon_{t+1}\right\}\right] \\
& =\exp \left\{-\delta_{0}+A_{n}+B_{n}^{\prime}\left(\mu-\Sigma \lambda_{0}\right)+\frac{1}{2} B_{n}^{\prime} \Sigma \Sigma^{\prime} B_{n}-\delta_{1}^{\prime} X_{t}+B_{n}^{\prime} \phi X_{t}-B_{n}^{\prime} \Sigma \lambda_{1} X_{t}\right\}
\end{aligned}
$$

Matching coefficients results in the recursive relations in equations (17).

The continuously compounded yield $y_{t}^{n}$ on an $n$-period zero coupon bond is given by:

$$
\begin{aligned}
y_{t}^{n} & =-\frac{\log p_{t}^{n}}{n} \\
& =A_{n}+B_{n}^{\prime} X_{t}
\end{aligned}
$$

\footnotetext{
${ }^{4}$ See the techniques in Campbell, Lo and MacKinlay (1997), Bekaert and Grenadier (2001) and Backus, Foresi, Mozumdar and Wu (2001).
} 
where $A_{n}=-\bar{A}_{n} / n$ and $B_{n}=-\bar{B}_{n} / n$. Note that yields are affine functions of the state $X_{t}$, so that equation (18) can be interpreted as being the observation equation of a state space system. Additional observation equations will come from the observable variables $X_{t}^{o}$. Most examples of discrete-time affine models have not incorporated lagged state variables or moving average errors. However, by treating both the lagged variables and moving average errors as state variables in $X_{t}$, the affine form is still maintained. Despite time-varying risk premia, our system is still Gaussian, and IR's, variance decompositions and other techniques can be handled as easily as an unrestricted VAR.

\subsection{Choice of Parameterization}

\subsubsection{Latent Variables}

Empirical studies have concluded that three unobserved factors explain much of yield dynamics (see Knez, Litterman and Scheinkman (1994)). To compare models with only latent variables with models incorporating both latent and macro factors we use three unobservable factors. Hence our most comprehensive model consists of two macro and three latent factors.

Since there are unobservable variables present, normalizations can be made that give observationally equivalent systems. The idea behind these normalizations in a VAR setting is that affine transformations and rotations of the unobservable factors lead to observationally equivalent yields. These normalizations are discussed in detail in Dai and Singleton (2000). We estimate the most general parameterization for the unobserved variables in this paper, and then re-estimate the system a second time while setting any insignificant parameters to zero. This is more efficient, ensures identification, allows comparison across models, and gives sufficient freedom to capture yield curve dynamics.

We estimate the following system for the unobservable factors:

$$
f_{t}^{u}=\rho f_{t-1}^{u}+u_{t}^{u}
$$

where $u_{t}^{u}$ IID N $(0,1)$ and the $3 \times 3$ companion matrix $\rho$ is lower triangular. This is the most general identified representation for a Gaussian specification. A multi-factor Vasicek (1977) model

with correlated unobservable factors consists of (19), an affine short rate equation (5), and the assumption that $\lambda_{1}=0$. In a Vasicek model, specifying the companion form and holding fixed the covariances is equivalent to holding the companion form fixed and specifying the covariances. As the latent factors are $\operatorname{AR}(1)$ processes, the coefficients $\Phi_{2} \ldots \Phi_{p}$, in equation (7) corresponding to $X_{t}^{u}=f_{t}^{u}$ are zero. Numerous papers in the term structure literature have used independent factors as a first-cut modeling approach, including Longstaff and Schwartz (1992) and Chen and Scott (1993). At the estimated parameters, however, the latent factors usually 
turn out to violate the independence assumption. We therefore estimate a correlated latent factor model to give the latent variables a fair chance to explain the yield curve by themselves, without the inclusion of macro variables.

We impose independence between latent and macro factors, so that the upper-right $24 \times 3$ corner and the lower-left $3 \times 24$ corner of $\Phi$ in the compact form in (8) contains only zeros. This approach to including observed macro factors in a pricing kernel specifies all uncertainties arising in the latent factors as orthogonal to the macro variables and can answer how yields respond to pure macro shocks. However, by assuming independence of latent and macro factors we cannot ask how macro factors respond to latent yield factors. This contradicts empirical evidence that the term structure predicts movements in macro economic activity (see Harvey (1988) and Estrella and Hardouvelis (1991)). Extensions of this model where this question can be addressed can be done by freeing up the companion matrix to allow feedback (so $\Phi$ does not contain zero corner blocks), and looking at contemporaneous correlations of macro and latent factors ( $\theta_{0}$ does not contain zero corner blocks). We leave extensions that free up correlations between factors for future research and focus on the impact of macro variables on yields.

\subsubsection{Risk Premia}

The data-generating and the risk neutral measures coincide if $\lambda_{t}=0$ for all $t$. This case is usually called the "Local Expectations Hypothesis," which differs from the traditional Expectations Hypothesis by Jensen inequality terms (see Cochrane (2001), Chapter 19). Macro models, such as Fuhrer and Moore (1995), usually impose the Expectations Hypothesis to infer long term yield dynamics from short rates. The dynamics of the term structure in the real measure depend on the risk premia parameters $\lambda_{0}$ and $\lambda_{1}$ in equation (11). A non-zero vector $\lambda_{0}$ affects the long-run mean of yields because this parameter affects the constant term in the yield equation (18). A non-zero matrix $\lambda_{1}$ affects the time-variation of risk-premia, since it affects the slope coefficients in the yield equation (18). In a Vasicek (1977) model $\lambda_{0}$ is non-zero and $\lambda_{1}$ is zero, which allows the average yield curve to be upward sloping, but does not allow risk premia to be time-varying.

Estimating prices of risk is difficult. Many estimations of term structure models with latent factors cannot reject the hypothesis that the market prices of risk are zero (for example, see the low t-statistics in Dai and Singleton (2000)). Parameter estimates of $\lambda_{0}$ and $\lambda_{1}$ are therefore interesting in themselves, because the evidence against the expectations hypothesis is still being debated. Although there is strong traditional evidence against it (Campbell and Shiller (1991)), newer evidence finds the expectations hypothesis much harder to reject in international data (Hardouvelis (1994)), or taking into account small-sample biases (see Bekaert and Hodrick (2001) and Bekaert, Hodrick, and Marshall (2001)). 
The number of $\lambda$ parameters to estimate is very large: $\lambda_{0}$ has 5 and $\lambda_{1}$ has 25 parameters in the case of the models with macro variables. To avoid over-fitting, we fix some of these parameters before estimation. First, we set any $\lambda_{1}$ parameters corresponding to the latent variables to zero in estimations of models with macro variables, if they were already insignificant in the Yields-Only estimation. We also specify the $\lambda_{1}$ matrix to be block-diagonal, with zero restrictions on the upper-right and lower-left corner blocks. This assumption is in the spirit of trying to let the macro variables characterize as much of the term structure dynamics as possible without resorting to orthogonal latent variables. Finally, we set all $\lambda_{1}$ parameters corresponding to lagged macro variables to zero. This leaves two non-zero matrices on the diagonal of $\lambda_{1}$ to estimate: a $2 \times 2$ matrix for current macro variables and a $3 \times 3$ matrix for the latent variables.

\subsection{Estimation Method}

To estimate the model, we transform a system of yields and observables $\left(Y_{t}, X_{t}^{o}\right)$ into a system of observables and unobservables $X_{t}=\left(X_{t}^{o}, X_{t}^{u}\right)$. The yields themselves are analytical functions of the state variables $X_{t}$, which allow us to infer the unobservable factors from the yields. The estimation method is maximum likelihood, and we derive the likelihood function in the Appendix. In traditional VAR approaches, yields and macro variables are used directly as inputs into a VAR after specifying the autoregressive lag length. The likelihood for the VAR is a function of $\left(Y_{t}, X_{t}^{o}\right)$, and inferences about yield curve movements and macro shocks can be drawn from the parameters in the companion form coefficients and covariance terms. Our approach amounts to estimating a VAR of $\left(Y_{t}, X_{t}^{o}\right)$, with assumptions that $(i)$ identify an unobservable component orthogonal to macro shocks and $(i i)$ guarantee no arbitrage.

We use a two-step consistent estimation procedure. In the first step, we estimate the macro dynamics (2) and the coefficients $\delta_{0}$ and $\delta_{11}$ of the macro factors in the short rate dynamics equation (6). In a second step, we estimate the remaining parameters of the term structure model holding all pre-estimated parameters fixed. One reason to do this is the difficulties associated with estimating a large number of factors simultaneously with maximum likelihood when yields are highly persistent. ${ }^{5}$ This procedure also avoids the estimation of a large number of lag coefficients $\left(\rho_{1}, \ldots \rho_{12}\right)$ in the bivariate VAR for the macro variables by maximizing a computationally intensive likelihood function.

Both the macro dynamics (2) and the short rate coefficients of the macro variables in equation (6) are estimated by ordinary least squares, as reported in Sections 2 and 3. Since our

\footnotetext{
${ }^{5}$ We tried to estimate various versions of the model in a single step with maximum likelihood. These estimations typically produced explosive yield dynamics. Fixing the parameters that characterize the dependence of the short rate on the observable factors in a (consistent) first-step estimation turned out to be a tractable way to avoid the problem of nonstationary dynamics.
} 
constructed macro factors have zero mean and unit variance, the constant $\delta_{0}$ in the short rate equation represents the unconditional mean of the 1 month yield, which equals $5.10 \%$ on an annualized basis. This number has to be divided by 12 to obtain an estimate for $\delta_{0}$ at a monthly frequency. The regression coefficients $\delta_{11}$ of the short rate equation give the maximal proportion of short rate movements explained by the macro factors, with all remaining orthogonal factors being unobservable. We use the term structure model to identify the unexplained proportion.

Holding $\delta_{0}, \delta_{11}$, and the parameters entering equation (2) fixed, we estimate all other parameters of the term structure model including the remaining coefficients in $\delta_{12}$ corresponding to the latent factors in the term structure estimation. To obtain starting values for $\rho$ in equation (19) we estimate the model with $\lambda_{0}$ and $\lambda_{1}$ equal to zero. We then estimate $\lambda_{1}$ still holding $\lambda_{0}$ fixed at zero. In the next estimation round, we estimate $\lambda_{0}$ while setting parameters in $\lambda_{1}$ that turned out to be insignificantly different from zero. We finally set insignificant $\lambda_{0}$ parameters to zero and re-estimate. This method gives more efficient estimates than a one-step estimation under the null that the insignificant parameters are equal to zero.

Finally, our likelihood construction solves for the unobservable factors from the joint dynamics of the zero coupon bond yields and the macro factors. To do this, we follow Chen and Scott (1993) and assume that as many yields as unobservable factors are measured without error, and the remaining yields are measured with error. In particular, for our models with three latent factors we assume the 1, 12 and 60-month yields are measured without error, and the 3 and 36-month yields are measured with error.

\subsection{Summary of Parameterization}

To summarize, we estimate the following special case of the general model. The bivariate system of macro factors $f_{t}^{o}$ follows the process:

$$
f_{t}^{o}=\rho_{1} f_{t-1}^{o}+\ldots+\rho_{12} f_{t-12}^{o}+\Omega u_{t}
$$

with $u_{t}$ IID N(0,I). The $2 \times 2$ matrices $\rho_{1}, \ldots, \rho_{12}, \Omega$ consist of free parameters.

The trivariate system of latent factors $f_{t}^{u}$ follows the process:

$$
f_{t}^{u}=\rho f_{t-1}^{u}+\epsilon_{t}
$$

with $\epsilon_{t}$ IID N(0,1). The $3 \times 3$ matrix $\rho$ is lower triangular to ensure identification. The shock processes $\epsilon_{t}$ and $u_{t}$ are independent.

The short rate equation is:

$$
r_{t}=\delta_{0}+\delta_{11}^{\prime} X_{t}^{o}+\delta_{12}^{\prime} X_{t}^{u}
$$


where the parameters $\delta_{0}$ and $\delta_{11}$ are consistently estimated by least squares in a first-step procedure prior to maximizing the likelihood. The observable factors are $X_{t}^{o}=\left(f_{t}^{o^{\prime}} f_{t-1}^{o^{\prime}} \ldots, f_{t-p}^{o^{\prime}}\right)$ and the latent factors are $X_{t}^{u}=f_{t}^{u}$. The full set of state variables is $X_{t}=\left(\left(X_{t}^{o}\right)^{\prime},\left(X_{t}^{u}\right)^{\prime}\right)^{\prime}$.

Market prices of risk are affine in the state vector:

$$
\lambda_{t}=\lambda_{0}+\lambda_{1} X_{t}
$$

The matrix $\lambda_{1}$ has an upper-left $2 \times 2$ matrix and a lower-right $3 \times 3$ matrix corresponding to $f_{t}^{o}$ and $f_{t}^{u}$, while the remaining parameters are set to zero. The parameters in $\lambda_{0}$ corresponding to $f_{t}^{o}$ and $f_{t}^{u}$ are free, and all remaining parameters are restricted to be zero.

Our most comprehensive model contains two macro factors and three unobservable factors, which we denote as the "Macro Lag" model. The estimation of $\delta_{11}$ that restricts the parameters on lagged parameters to be zero as in equation (22) is denoted the "Macro" model. The estimation without any macro variables we call the "Yields-Only" model.

\section{Estimation Results}

Section 5.1 interprets the parameter estimates of the Macro and Yields-Only models. To determine the effect of the addition of macro factors into term structure models, we look at the IR's of each factor in Section 5.2. The variance decompositions in Section 5.3 allow us to attribute the forecast variance at a particular horizon to shocks in macro and latent factors. We compare the latent factors from the different models in Section 5.4 and find that macro factors do account for some of the latent factors from the Yields-Only model. In Section 5.5, we find that imposing the cross-equation restrictions from no-arbitrage forecasts better than the unrestricted VAR's common in the macro literature. Moreover, incorporating macro variables into a term structure model helps us obtain even better forecasts. Derivations for the IR's and variance decompositions are presented in the Appendix.

\subsection{Parameter Estimates}

\subsubsection{Yields-Only Model}

Table 5 presents the estimation results for the Yields-Only Model. The order of the latent factors in Table 5 is unspecified, but we present the estimation results by ordering the latent factors by decreasing autocorrelation. The model has one very persistent factor, one less persistent but still very strongly persistent factor, and the last factor is strongly mean-reverting. This is consistent with previous multi-factor estimates in the literature such as Chen and Scott (1993). 
These unobservable factors have been labeled "level," "slope," and "curvature" respectively because of the effects of these factors on the yield curve. In Figure 5 we plot the normalized factors against three normalized transformations of the 1 month, 12 month and 60 month yields $\left(y_{t}^{1}, y_{t}^{12}\right.$ and $y_{t}^{60}$ respectively). The first latent variable, Unobs 1 , closely corresponds to a "level" effect, which is defined as $1 / 3\left(y_{t}^{1}+y_{t}^{12}+y_{t}^{60}\right)$. The correlation between Unobs 1 and the level transformation is $92 \%$. The second latent variable, Unobs 2, closely corresponds to a "spread" transformation, defined as $y_{t}^{60}-y_{t}^{1}$. Unobs 2 and the spread have a correlation of $58 \%$. Finally, the third latent variable, Unobs 3 , is related to a "curvature" transformation, defined as $y_{t}^{1}-2 y_{t}^{12}+y_{t}^{60}$. Unobs 3 has a $77 \%$ correlation with curvature. ${ }^{6}$

In Table 5, the estimated vector $\lambda_{0}$ has one significant parameter corresponding to the most highly autocorrelated factor. The parameter is negative, so that the unconditional mean of the short rate under the risk-neutral measure is higher than under the data-generating measure. Since bond prices are computed under the risk-neutral measure, negative parameters in $\lambda_{0}$ induce long yields to be on average higher than short yields. Time-variation in risk premia is mainly driven by the first and third unobservable factor. In other words, risk premia in bond yields mainly depend on the level and the curvature of the yield curve.

\subsubsection{Models with Yields and Macro Variables}

Tables 6 and 7 contain estimation results of the Macro Model and the Macro Lag Model. The autocorrelations of the unobservable factors are comparable across all models, with the exception of Unobs 3. The autocorrelation of Unobs 3 is approximately the same in the Yields-Only and Macro Model (0.7646 and 0.7728 respectively) but is more persistent in the Macro Lag Model (0.8210). The $\delta_{1}$ coefficients corresponding to latent factors are also approximately the same across the three models.

Turning to the risk premia parameters in Tables 6 and 7, the $\lambda_{1}$ coefficients corresponding to inflation and real activity are significant. This implies that time-variation in risk premia significantly depends on observable macro factors. However, the estimates of the $\lambda_{1}$ risk parameters differ across the Macro and Macro Lag Model. In particular, the inflation-real activity crossterms $\left(\lambda_{1,12}\right.$ and $\left.\lambda_{1,21}\right)$, where the additional two subscripts denote matrix elements, are much larger in absolute magnitude in the Macro Model than in the Macro Lag Model. Similarly, the inflation and real activity diagonal terms $\left(\lambda_{1,11}\right.$ and $\left.\lambda_{1,22}\right)$ are smaller in the Macro Model estimation than in the Macro Lag Model. This implies that the behavior of inflation and real activity on the term structure may be potentially quite different across the Macro and Macro

\footnotetext{
${ }^{6}$ For comparison, the standard Knez, Litterman and Scheinkman (1994) three principal components of the 1 month, 12 month and 60 month yields have correlations $100 \%, 99.8 \%$ and $88.6 \%$ with the level, spread and curvature yield transformations.
} 
Lag Models. We confirm this in the following sections where we examine IR's and variance decompositions. In contrast, the $\lambda_{1}$ parameters corresponding to the latent factors are roughly similar across the Macro and Macro Lag Models, with the exception of the Unobs 3 diagonal term $\left(\lambda_{1,55}\right)$.

\subsection{Impulse Responses}

\subsubsection{Factor Weights Across the Yield Curve}

From equation (18), the effect of each factor on the yield curve is determined by the weights $B_{n}$ that the term structure model assigns on each yield of maturity $n$. These weights $B_{n}$ also represent the initial response of yields to movements in the various factors. Figure 6 plots these weights as a function of yield maturity for the Yields-Only model in the upper graph, and the Macro Model in the lower graph. The $B_{n}$ coefficients have been scaled to correspond to movements of one standard deviation of the factors, and have been annualized by multiplying by 1200 .

Turning first to the Yields-Only model, the weight on the most persistent factor (Unobs 1) is almost horizontal. This means that it affects yields of all maturities the same way, so we can call it a level factor. The coefficient of the second factor (Unobs 2) is upward sloping. It mainly moves the short end of the yield curve relative to the long end, so Unobs 2 is therefore a slope factor. The coefficient on the least persistent factor (Unobs 3) is hump-shaped. Movements in this factor affect yields at the short-end of the yield curve and middle and long-end of the yield curve with different signs. Hence, the $B_{n}$ weights corresponding to Unobs 3 have a twisting effect, so Unobs 3 is thus a curvature factor. The inverse hump in the coefficient of this factor cannot be accommodated in a model with independent factors and constant risk premia, where yield coefficients are monotone functions of maturity.

The corresponding coefficients of the Macro model in the lower plot in Figure 6 look very similar. We again find that Unobs 1 though 3 represent level, slope and curvature factors. We find the same correspondence in the $B_{n}$ coefficients of the Macro Lag model (which we do not graph here). The $B_{n}$ coefficients corresponding to inflation and real activity we represent as stars and circles, respectively. The effect of inflation is hump-shaped but mostly affects short

yields and less so long yields. The magnitude of the inflation weights are higher than the level factor weights at short maturities, and about half the magnitude of the slope factor weights. Real activity has a much weaker hump-shaped effect on the yield curve. This suggests that macro factors have much explanatory power for yield curve dynamics. To trace out the long-term responses of the yield curve from shocks to the macro variables after the yield curve's initial response, we now compute IR's. 


\subsubsection{Impulse Responses from Macro Shocks}

We look at IR's to yields of maturities 1, 12 and 60 months. Our term structure model allows us to obtain the movements of the yield curve in response to driving shocks at all horizons, including maturities omitted in estimation. The IR's for all maturities are known analytical functions of the parameters. This is in contrast to estimations with VAR's where IR's can only be calculated for yields included in the VAR. Our estimation also guarantees that the movements of yields are arbitrage-free.

Figure 7 shows IR's of 1, 12 and 60 month yields from the Macro model and the Macro Lag model. In addition, we calculate the IR's from a simple unrestricted VAR(12), with macro factors and 5 yields similar to Campbell and Ammer (1993). We order the variables with macro factors first, and then yields with increasing maturities. The $x$-axis on each plot is in months and the IR's are given in terms of annualized percentages for a shock of one standard deviation.

In all models, shocks to inflation and real activity raise the yield curve across all maturities, with a larger response to inflation shocks. The IR's of macro shocks are hump-shaped in all models. The hump in the unrestricted response to real activity shocks occurs after one year, while the hump in the response to inflation shocks occurs later, after two years. The magnitudes and the exact location of the humps differ across models.

Turning first to the IR's of the unrestricted VAR in the first column of Figure 7, a onestandard deviation shock to inflation initially raises the 1-month yield about 10 basis points. The response peaks after about two years at 30 basis points and then slowly levels off. The response of longer yields has the same overall shape. The initial response of the 1-year yield (5-year yield) is only 8 basis points ( 5 basis points). The response increases to around 25 basis points (22 basis points) after two years, and then dies off slowly. The response of yields to real activity shocks in the unrestricted VAR is slightly smaller than the response to inflation shocks. The response is again hump-shaped with the hump occurring after one year. The unrestricted response of the 1-month yield to a 1 standard deviation output shock is around 15 basis points initially. The response increases to 30 basis points after two years, and then dies off. The initial responses of the 1-year yield (5-year yield) is 15 (10) basis points. The response increases to 25 (18) basis points after one year and then dies off.

The last two columns of Figure 7 list IR's in the Macro and Macro Lag models. The humpshape of the IR's are similar to the shape of the IR's from the unrestricted VAR, but the IR's are much larger. For example, the initial response of the 1-year yield to a 1 standard deviation inflation shock is 50 basis points in the Macro model. The response then increases to almost 1 percentage point after one year, where it peaks. The hump in the IR to inflation shocks in the Macro Lag model occurs later, after 2 years, and is therefore similar to the pattern in the 
unrestricted response. The IR's from the Macro Lag model, however, are more erratic than those of the Macro model. This is because the contemporaneous and 11 lags of the short rate equation contain many insignificant parameters, which cause poor behavior due to over-parameterization.

Our results are different from the empirical VAR studies such as Evans and Marshall (2000). They associate shocks to price levels and economic growth as having a level-shift effect across the yield curve. We find that shocks to these factors generally affect the short yield end of the yield curve more than the long end of the yield curve. The structure in Evans and Marshall (2000) is to construct VAR's for yields with macro variables and a monetary policy proxy (the federal funds rate). In our model, most of the movement in the yield curve at long horizons is explained by unobserved factors, whereas in the VAR most movements in the term structure are unexplained and are absorbed by the VAR as covariance error. When estimating the model, the first unobservable factor mimics the level of the term structure because this is the linear combination that looks like the first principal component of yields, which the macro factors cannot replicate. This factor is very persistent, and affects the long end of the yield curve more than the short end.

\subsection{Variance Decompositions}

To gauge the relative contributions of the macro and latent factors to forecast variances we construct variance decompositions. These show the proportion of the forecast variance attributable to each factor, and are closely related to the IR's of Section 5.2. Table 8 summarizes our results. The proportion of unconditional variance accounted for by macro factors is decreasing with the maturity of yields: highest at the short and middle-ends of the yield curve, and smallest for the long-end. The largest effect is on the 1-month yield where macro factors account for $83 \%$ of the unconditional variance (where the forecasting horizon is infinite). The proportion of forecast variance explained by macro factors displays an interesting pattern for different parts of the yield curve. For short and intermediate maturities, this pattern is hump-shaped. For example, macro factors account for $50 \%$ of the 1-step ahead forecast variance of the 1-month yield. This percentage rises to $78 \%$ at 12 months and $85 \%$ at 60 months, but then converges to $83 \%$ for extremely long horizons. For long yields, the explanatory power of the macro variables decreases with forecasting horizon. Macro variables only account for $40 \%$ of the unconditional variance of long yields, while the rest is attributed to latent factors. The low variance decomposition of long yields is due to the dominance of persistent unobserved factors (the near unit-root factor). Overall, Table 8 shows that the macro factors explain a large amount of term structure movements, particularly at the short and middle parts of the yield curve.

More detailed variance decompositions are listed in Table 9 for 1, 12 and 60 month maturities. To interpret the top row of Table 9, for the Yields-Only model, 13.81\% of the 1-step ahead 
forecast variance of the 1-month yield is explained by the first unobserved factor, $33.03 \%$ by the second unobserved factor and $53.14 \%$ by the third unobserved factor. In the row labeled $h=1$ of the Macro Model in the first panel corresponding to the 1-month yield, $48.87 \%$ of the 1-step ahead forecast variance is attributable to inflation, $0.74 \%$ to real activity and the remainder to the latent factors.

Focusing on the Macro Model, inflation has more explanatory power for forecast variances than real activity at all points of the yield curve and for all forecast horizons. For example, at the 12-month horizon $68.60 \%(9.46 \%)$ of the forecast variance of the 1-month yield is accounted for by inflation (economic growth). The explanatory power of real activity generally rises with the forecast interval $h$. At the long end of the yield curve the explanatory power of inflation decreases with $h$. Inflation and real activity remain important in the Macro Lag Model, but the proportion attributable to macro variables is much smaller for the 60 month yield than the Macro Model.

Turning now to the latent factors in Table 9, Unobs 1, corresponding to the first highly persistent latent factor, dominates the variance decompositions for all the yields at long horizons. Its importance increases for yields with long maturity. This effect mirrors the flat $B_{n}$ yield factor weights in Figure 6. The second unobserved factor (Unobs 2) has greatest effect on short-run flucations of yields with intermediate maturities. The third unobserved factor (Unobs 3 ) is the strongly mean-reverting factor and acts only on the short end of the yield curve. In Table 9 it accounts for $53 \%$ of the forecast variance for the 1-month yield at a one month horizon, but has little effect on longer yields. These patterns are mirrored in both the Yields-Only model and models with macro variables, but with different magnitudes. These variance decompositions suggest that the role of the "level" factor (Unobs 1), "butterfly" factor (Unobs 2) and "slope" factor (Unobs 3) remain roughly the same with the addition of macro factors. The next section seeks to quantify the change in the behavior of these unobserved factors in the presence of macro variables.

\subsection{Comparison of Factors}

The addition of macro factors into a term structure model is shown quantatively in Table 10. In this table we regress the latent factors from the Yields-Only model onto the macro and latent factors from the Macro and Macro Lag Models. We run three series of regressions, first only on the macro variables (Panel A), and then onto the macro and latent variables of the Macro Model (Panel B), and then onto the macro and latent variables of the Macro Lag Model (Panel C). All the variables in the regressions are normalized.

Turning first to Panel A of Table 10, the traditional level factor loads significantly onto 
inflation and real activity, with an adjusted $R^{2}$ of $22 \%$. In particular, the loading on inflation is positive and large (0.46). This suggests that the traditional level factor captures a strong inflation effect. When the second latent factor, labeled "slope," is regressed onto the macro factors, we obtain a high $R^{2}$ of $49 \%$, with significant negative loadings particularly on inflation (-0.67). Hence, much of the traditional slope factor is also related to the dynamics of inflation. Finally, the third latent factor ("curvature") is poorly accounted by macro factors $R^{2}=3 \%$. However, the traditional curvature factor does load significantly onto real activity.

Panel B of Table 10 reports the regression from the traditional Yields-Only factors onto the macro and latent factors implied by the Macro Model. The level factor from the Yields-Only model translates almost one for one with the level factor of the Macro Model. The magnitude of the coefficient on Unobs 1 of the Macro model is very close to 1, and the full regression produces an $R^{2}$ of $99 \%$. However, the loadings on the macro factors are significant suggesting that macro variables do account for some of the level factor.

The reason why the level factor survives almost intact when macro factors are introduced is because the level factor proxies for the first principal component of the yield curve, as shown in Figure 5. The unobservable factors are linear combinations of the yields, and the best linear combination of yields which explains term structure movements is the first principal component. When macro factors are added, these factors still do not resemble the level of the yield curve, and so this factor is still necessary to explain the movements across the term structure.

When we regress the Yields-Only slope factor (Unobs 2) onto the Macro Model factors the loading of the Unobs 2 factor from the Macro Model is significantly smaller than 1, while the coefficient on inflation is very large and negative, and the coefficient on real activity is also significant. This means that a large part of the traditional slope factor can be attributed to inflation movements. In particular, when inflation is high, the slope narrows because the short rate increases relative to the long rate. Turning finally to the regression of the Yields-Only curvature factor (Unobs 3), this regression still has a significant negative coefficient on real activity, but most of the correspondence is with the Unobs 3 factor from the Macro Model (the coefficient is 0.91 ).

Panel C of Table 10 reports the regression coefficients of the latent factors from the YieldsOnly model onto the macro and latent factors of the Macro Lag Model. We see that the level effect again survives almost one for one and there is still a large loading on the inflation factor by the Yields-Only model's Unobs 2. However, the $R^{2}$ 's of the Unobs 2 and Unobs 3 regressions are much smaller than the Macro Model regressions in Panel B.

In summary, Table 10 shows that the traditional level and slope factors are markedly associated with and accounted by observable macro factors. In particular, inflation accounts for 
large amounts of the dynamics of the traditional slope factor. However, the level effect survives almost intact when macro factors are added to a term structure model.

\subsection{Forecasts}

The variance decompositions hint that term structure models with observable macro variables may help in forecasting future movements in yields. However, these are statements based on assuming a particular model as the true model after estimation, and may not hold in a practical setting where more parsimonious data representations often out-perform sophisticated models, particularly if these more sophisticated models are over-parameterized. To determine if this is actually the case we conduct an out-of-sample forecasting experiment.

Our procedure for examining out-of-sample forecasts over the last 5 years of our sample is as follows. We examine forecasts for all the five yields used in estimation. At each date $t$, we estimate the models using data up to and including time $t$, and then forecast the next month's yields at time $t+1$. The macro factor data is formed using the principal components of the macro data up to time $t$, and we estimate the short rate equation and the bivariate VAR of the macro dynamics only using data up to time $t$ for the Macro and Macro Lag Models. Hence, we only use data available in the information set at time $t$ in making the forecast at time $t+1$.

We perform a comparison of out-of-sample forecasts for six models. First, we use a simple random walk. Second, we investigate out-of-sample forecasts for the corresponding VAR(12)'s which do not impose cross-equation restrictions. Our first VAR uses only yields, and we use a second VAR which incorporates yields and macro variables. Our last three models are the Yields-Only model, the Macro model and the Macro Lag model. We use two criteria to compare our forecasts across the models. The first is the Root Mean Squared Error, RMSE, of actual and forecasted yields, and the second is the Mean Absolute Deviation, MAD.

Table 11 lists the results of the out-of-sample comparisons. Lower RMSE and MAD values denote better forecasts. We note the following points regarding the forecasting performance of the models. First, a random walk easily beats an unconstrained VAR. The result holds independently of whether the VAR's only contain yields, or are augmented with macro variables. The bad performance is due to the high persistence of yields and small sample biases in the estimation of autoregressive coefficients in over-parameterized VAR's.

Second, imposing the cross-equation restrictions from no-arbitrage helps in forecasting. The improvement in forecasting performance is substantial, generally about $25 \%$ of the RMSE and $30 \%$ of the MAD for all yields. These constrained VAR's perform in line with, and slightly better, than a random walk (except for the 3-month yield). Duffee (2001) remarks that beating 
a random walk with a traditional affine term structure model is difficult. From forecasting exercises without risk premia (not reported here), we know that this result crucially depends on the type of risk adjustment. Linear risk premia, not considered by Duffee (2001), seem to do well in this regard.

Third, the forecasts of the Macro model are far better than those of the Macro Lag model. While the forecasts of the Macro Lag model are comparable to those of unconstrained VAR's, the Macro model slightly outperforms a random walk (except for the 3-month yield). Both the Macro model and the Macro Lag model impose cross-equation restrictions on a VAR with yields and macro variables. The Macro Lag model, however, has a large number of insignificant coefficients entering the short rate equation. This over-parameterization causes poor out-ofsample performance.

Finally, incorporating macro variables helps in forecasting. More precisely, the forecasts of the Macro model are uniformly better than the Yields-Only model (except for the 3 month yield). Hence, we can conclude that $(i)$ adding term structure restrictions improves forecasts relative to unconstrained VAR's, even beating a random walk, and ( $i i$ ) forecasts can be further improved by including macro variables. Note, however, that we have shown this improvement is only in incrementally adding macro factors to a given number of latent factors.

\section{Conclusion}

This paper presents a Gaussian model of the yield curve with observable macroeconomic variables and traditional latent yield variables. The model takes a first step towards understanding the joint dynamics of macro variables and bond prices in a factor model of the term structure. Risk premia are time-varying; they depend on both observable macro variables and unobservable factors. Our approach extends the existing empirical VAR work by imposing no-arbitrage assumptions which allow identification of unobservable factors, and allows the movements of the entire yield curve to be derived consistent with no-arbitrage.

We find that macro factors explain a significant portion (up to 85\%) of movements in the short and middle parts of the yield curve, but explain only around $40 \%$ of movements at the long end of the yield curve. The effects of inflation shocks are strongest at the short end of the yield curve. Comparing the latent factors from traditional three latent factor models of term structure, the "level" factor survives almost intact when macro factors are incorporated, but a significant proportion of the "level" and "slope" factors are attributed to macro factors, particularly to inflation. Incorporating macro factors in a term structure model also improves out-of-sample forecasts. 
In future research, we plan to extend our empirical specification to allow non-diagonal terms in the companion form for the factors. This introduces correlations among the latent factors and feedback from latent factors to macro variables. This allows inference of how latent yield factors drive macro variables, along the lines of Estrella and Hardouvelis (1991) but with the dynamics of the yield curve modeled in a no-arbitrage pricing approach. 


\section{Appendix}

\section{A Likelihood Function}

We have data on an $N$ vector of zero coupon yields $Y_{t}$. Our approach to estimation is to solve for the unobserved factors $f_{t}^{u}$ from the yields $Y_{t}$ and the observed variables $X_{t}^{o}$, which includes observed macro variables $f_{t}^{o}$ and latent variables $f_{t}^{u}$ and lagged terms of the driving factors.

Suppose first that we have $N=K_{2}$ yields of different maturity $n_{1}, \ldots, n_{K_{2}}$, as many yields as we have unobserved factors, $f_{t}^{u}$. Stacking the equations for the $K_{2}$ yields, with $Y_{t}=\left(y_{t}^{n_{1}} \ldots y_{t}^{n_{K_{2}}}\right)^{\prime}$, we can write:

$$
Y_{t}=A+B X_{t},
$$

where $A$ is $K_{2} \mathrm{x} 1$ and $B$ is $K_{2} \mathrm{x} K$. Partition the matrix $B$ into $B=\left[B^{o} B^{u}\right]$ where $B^{o}$ is a $K_{2} \times\left(K-K_{2}\right)$ matrix which picks up the observable factors and $B^{u}$ is a $K_{2} \times K_{2}$ invertible matrix that picks up the unobservable factors. Then we can infer the unobservable factors in $X_{t}^{u} \equiv f_{t}^{u}$ from $Y_{t}$ and the pricing matrices $A$ and $B$ using an inversion from the equation:

$$
Y_{t}=A+B^{o} X_{t}^{o}+B^{u} X_{t}^{u} .
$$

However, the term structure model will only price exactly the yields used to invert the latent factors. To increase the number of yields to $N \geq K_{2}$ in the estimation, we follow Chen and Scott (1993), and others, in assuming that some of the yields are observed with measurement error. There will be $K_{2}$ yields from which we invert to obtain the latent variables, and the other $N-K_{2}$ yields are measured with error. We assume this measurement error is IID, and the measurement error is uncorrelated across the yields measured with error. Let $B^{m}$ denote a $N \times\left(N-K_{2}\right)$ measurement matrix and $u_{t}^{m}$ be an $\left(N-K_{2}\right)$-dimensional Gaussian white noise with a diagonal covariance matrix independent of $X_{t}$. We can then write:

$$
Y_{t}=A+B^{o} X_{t}^{o}+B^{u} X_{t}^{u}+B^{m} u_{t}^{m} .
$$

In equation (A-3) the yields measured without error will be used to solve for $X_{t}^{u}$, and the yields measured with error have non-zero $u_{t}^{m}$. For a given parameter vector $\theta=\left(\mu, \Phi, \Sigma, \delta_{0}, \delta_{1}, \lambda_{0}, \lambda_{1}\right)$, we can invert equation (A-3) to obtain $X_{t}^{u}$ and $u_{t}^{m}$. The variance of the measurement error in our estimations are very small and choosing different bonds to be measured without error do not affect our results.

Denoting the normal density functions of the state variables $X_{t}$ and the errors $u_{t}^{m}$ as $f_{X}$ and $f_{u^{m}}$ respectively, the joint likelihood $\mathfrak{L}(\theta)$ of the observed data on zero coupon yields $Y_{t}$ and the observable factors $X_{t}^{o}$ is given by:

$$
\begin{aligned}
\mathfrak{L}(\theta))= & \prod_{t=2}^{T} f\left(Y_{t}, X_{t}^{o} \mid Y_{t-1}, X_{t-1}^{o}\right) \\
\log (\mathfrak{L}(\theta))= & \sum_{t=2}^{T}-\log |\operatorname{det}(J)|+\log f_{x}\left(X_{t}^{o}, X_{t}^{u} \mid X_{t-1}^{o}, X_{t-1}^{u}\right)+\log f_{u^{m}}\left(u_{t}^{m}\right) \\
= & -(T-1) \log |\operatorname{det}(J)|-(T-1) \frac{1}{2} \log \left(\operatorname{det}\left(\Sigma \Sigma^{\prime}\right)\right) \\
& -\frac{1}{2} \sum_{t=2}^{T}\left(X_{t}-\mu-\Phi X_{t-1}\right)^{\prime}\left(\Sigma \Sigma^{\prime}\right)^{-1}\left(X_{t}-\mu-\Phi X_{t-1}\right) \\
& -\frac{T-1}{2} \log \sum_{i=1}^{N-K_{2}} \sigma_{i}^{2}-\frac{1}{2} \sum_{t=2}^{T} \sum_{i=1}^{N-K_{2}} \frac{\left(u_{t, i}^{m}\right)^{2}}{\sigma_{i}^{2}}
\end{aligned}
$$

where $\sigma_{i}^{2}$ is the variance of the $i$-th measurement error and the Jacobian term is given by

$$
J=\left(\begin{array}{ccc}
I & 0 & 0 \\
B^{o} & B^{u} & B^{m}
\end{array}\right) .
$$

Note that the Jacobian terms of the likelihood in equation (A-4) do not involve $A_{n}$, and hence the constant prices of risk $\lambda_{0}$ but do involve the linear prices of risk $\lambda_{1}$. 


\section{B Impulse Responses}

To derive the IR's of the yields from shocks to the macro variables and latent yield factors $F_{t}=\left(f_{t}^{o^{\prime}}, f_{t}^{u^{\prime}}\right)^{\prime}$ consider the $\operatorname{VAR}(12)$ form of $F_{t}$ in equation (7), repeated here:

$$
F_{t}=\Phi_{0}+\Phi_{1} F_{t-1}+\ldots+\Phi_{p} F_{t-12}+\theta_{0} u_{t}
$$

The $\Phi_{i}$ coefficients take the following form in our parameterization:

$$
\Phi_{0}=0 \quad \Phi_{1}=\left(\begin{array}{cc}
\rho_{1} & 0 \\
0 & \rho
\end{array}\right) \quad \Phi_{i}=\left(\begin{array}{cc}
\rho_{i} & 0 \\
0 & 0
\end{array}\right) \text { for } i=2, \ldots, 12 .
$$

We write this as an implied Wold $\mathrm{MA}(\infty)$ representation:

$$
F_{t}=\sum_{i=0}^{\infty} P_{i} u_{t-i},
$$

where $u_{t}=\left(u_{t}^{o^{\prime}} u_{t}^{u^{\prime}}\right)^{\prime}$ are the shocks to $F_{t}$. Note that a Choleski adjustment is needed to take into account the contemporaneous correlation of the shocks.

The yield on an $n$-period zero coupon bond $y_{t}^{n}$ is a linear combination of current and lagged values of $u_{t}$ from equation (18), which we can write as:

$$
y_{t}^{n}=A_{n}+\sum_{i=0}^{\infty} \psi_{i}^{n} u_{t-i},
$$

where the row vectors $\psi_{i}^{n}$ are functions of $B_{n}$. Note that this is just a linear transformation of the original $\mathrm{MA}(\infty)$ form, and the $B_{n}$ are closed-form from equation (17).

For example, for the Macro Model, the state-space $X_{t}$ is given by:

$$
X_{t}=\left(f_{t}^{o^{\prime}} f_{t-1}^{o^{\prime}} \ldots f_{t-12}^{o^{\prime}} f_{t}^{u^{\prime}}\right)^{\prime},
$$

where $f_{t}^{o}$ are the two macro factors, and $f_{t}^{u}$ are the three unobservable factors. The yields for maturity $n, y_{t}^{n}$, can be written as:

$$
\begin{aligned}
y_{t}^{n} & =A_{n}+B_{n}^{\prime} X_{t} \\
& =A_{n}+B_{n 1}^{\prime} f_{t}^{o}+\cdots+B_{n 12}^{\prime} f_{t-12}^{o}+B_{n 13}^{\prime} f_{t}^{u} \\
& =A_{n}+\bar{B}_{n 1}^{\prime} F_{t}+\cdots+\bar{B}_{n 12}^{\prime} F_{t-12}
\end{aligned}
$$

where we partition as $B_{n}=\left[B_{n 1} \ldots B_{n 13}\right]$, where $B_{n i}$ corresponds to $f_{t-i}^{o}$ for $i=0, \ldots, 12$ and $B_{n 13}$ corresponds to $f_{t}^{u}$, and $\bar{B}_{n 1}=\left[B_{n 1} B_{n 13}\right]$, and $\bar{B}_{n i}=\left[B_{n i} 0\right]$ for $i=2, \ldots 12$.

Then substituting the $\mathrm{MA}(\infty)$ representation for $F_{t}$ we have:

$$
\begin{aligned}
\psi_{0}^{n} & =\bar{B}_{n 1}^{\prime} P_{0} \\
\psi_{1}^{n} & =\bar{B}_{n 1}^{\prime} P_{1}+\bar{B}_{n 2}^{\prime} P_{0} \\
& \vdots \\
\psi_{i}^{n} & =\bar{B}_{n 1}^{\prime} P_{i-1}+\cdots+\bar{B}_{n 12}^{\prime} P_{i-12}, \text { for } i \geq 12 .
\end{aligned}
$$

and so on.

The vector $\psi_{i}^{n}$ is the IR for the $n$-period yield at horizon $i$ for shocks to the driving variables $F_{t}$ at time 0 . For $k$ yields of maturities $n_{1}, \ldots n_{k}$, we can stack the coefficients of each yield to write:

$$
Y_{t}=A+\sum_{i=0}^{\infty} \Psi_{i} u_{t-i}
$$

where $Y_{t}=\left(y_{t}^{n_{1}} \ldots y_{t}^{n_{k}}\right)^{\prime}$ and the $j$-th row of $\Psi_{i}$ is $\psi_{i}^{n}$. 


\section{Variance Decompositions}

Working with the $\operatorname{MA}(\infty)$ representation of the yields in equation (B-10), the error of the optimal $h$-step ahead forecast at time $t, \hat{Y}_{t+h \mid t}$ is:

$$
\hat{Y}_{t+h \mid t}-Y_{t+h}=\sum_{i=0}^{h-1} \Psi_{i} u_{t+h-i}
$$

Let the $j$-th component of a vector be denoted by a superscript $j$ and $\Psi_{j k, i}$ denote the element in row $j$, column $k$ of $\Psi_{i}$. Then:

$$
\hat{Y}_{t+h \mid t}^{j}-Y_{t+h}^{j}=\sum_{k=1}^{K}\left(\Psi_{j k, 0} u_{t+h}^{k}+\ldots \Psi_{j k, h-1} u_{t+1}^{k}\right)
$$

Denote the mean squared error of $\hat{Y}_{t+h \mid t}^{j}$ as $\operatorname{MSE}\left(\hat{Y}_{t+h \mid t}\right)$. Then

$$
\operatorname{MSE}\left(\hat{Y}_{t+h \mid t}\right)=\sum_{k=1}^{K}\left(\Psi_{j k, 0}^{2}+\cdots+\Psi_{j k, h-1}^{2}\right) .
$$

The contribution $\Omega_{j k, h}$ of the $k$-th factor to the MSE of the $h$-step ahead forecast of the $j$-th yield is:

$$
\Omega_{j k, h}=\frac{\sum_{i=0}^{h-1} \Psi_{j k, i}^{2}}{\operatorname{MSE}\left(\hat{Y}_{t+h \mid t}\right)},
$$

which decomposes the forecast variance at horizon $h$ of the $j$-th yield to the various factors. 


\section{References}

Ang, A., and G. Bekaert, 1998, "Regime Switches in Interest Rates,” NBER working paper 7056.

Backus, D., S. Foresi, A. Mozumdar, and L. Wu, 2001, "Predictable Changes in Yields and Forward Rates," Journal of Financial Economics, 59, 281-311.

Bekaert, G., and S. Grenadier, 2001, "Predictability of Bond and Stock Returns in Affine Models," working paper, Columbia University.

Bekaert, G., and R. J. Hodrick, 2001, "Expectations Hypotheses Tests," forthcoming Journal of Finance.

Bekaert, G., R. J. Hodrick, and D. A. Marshall, 2001, “ “Peso Problem” Explanations for Term Structure Anomalies,” forthcoming Journal of Monetary Economics.

Bernanke, B. S. and I. Mihov, 1995, “Measuring Monetary Policy,” NBER Working Paper 5145.

Campbell, J. Y., and J. Ammer, 1993, "What Moves the Stock and Bond Markets? A Variance Decomposition for Long-Term Asset Returns," Journal of Finance, 48, 1, 3-37.

Campbell, J. Y., A. W. Lo, and A. C. MacKinlay, 1997, The Econometrics of Financial Markets, Princeton University Press.

Campbell, J. Y., and R. J. Shiller, 1991, "Yield Spreads and Interest Rate Movements: A Bird's Eye View," Review of Economic Studies, 58, 495-514.

Chen, R. R., and L. Scott, 1993, "Maximum Likelihood Estimation for a Multi-factor Equilibrium Model of the Term Structure of Interest Rates," Journal of Fixed Income, 3, 14-31.

Christiano, L., M. Eichenbaum, and C. Evans, 1996a, "The Effects of Monetary Policy Shocks: Evidence from the Flow of Funds," Review of Economics and Statistics, 78, 16-34.

Christiano, L., M. Eichenbaum, and C. Evans, 1996b, "Identification and the Effects of Monetary Policy Shocks," in eds. Blejer, M., Z. Eckstein, Z. Hercowitz, and L. Leiderman, Financial Factors in Economic Stabilization and Growth.

Christiano, L., M. Eichenbaum, and C. Evans, 1998, "Monetary Policy Shocks: What Have we Learned and to What End?" NBER working paper 6400.

Clarida, R., J. Gali and M. Gertler, 2000, "Monetary Policy Rules and Macroeconomic Stability: Evidence and Some Theory.” Quarterly Journal of Economics, 65, 1, 147-180.

Cochrane, J. H., 1998, "What do the VAR's mean? Measuring the Output Effects of Monetary Policy," Journal of Monetary Economics, 41, 277-300.

Cochrane, J. H., 2001, Asset Pricing, Princeton University Press.

Constantinides, G. M., 1992, “A Theory of the Nominal Term Structure of Interest Rates," Review of Financial Studies, 5, 4, 531-52.

Dai, Q., and K. Singleton, 2000, "Specification Analysis of Affine Term Structure Models," Journal of Finance, $55,5,1943-1978$.

Dai, Q., and K. Singleton, 2001, "Expectation Puzzles, Time-varying Risk Premia, and Affine Models of the Term Structure," forthcoming Journal of Financial Economics.

Duffee, G. R., 2001, “Forecasting Future Interest Rates: Are Affine Models Failures?,” forthcoming Journal of Finance.

Duffie, D., and R. Kan, 1996, “A Yield-Factor Model of Interest Rates,” Mathematical Finance, 6, 4, 379-406.

El Karoui, N., R. Myneni, and R. Viswanathan, 1992, "Arbitrage Pricing and Hedging of Interest Rate Claims with State Variables I: Theory," working paper, Université de Paris VI, Laboratoire de Probabilité.

Estrella, A., and G. A. Hardouvelis, 1991, "The Term Structure as a Predictor of Real Economic Activity," Journal of Finance, 46, 2, 555-576.

Estrella, A., and F. S. Mishkin, 1997, "The Predictive Power of the Term Structure of Interest Rates in Europe and the United States: Implications for the European Central Bank," European Economic Review, 41, 7, $1375-1401$. 
Evans, C. L., and D. A. Marshall, 1998, "Monetary Policy and the Term Structure of Nominal Interest Rates: Evidence and Theory," Carnegie-Rochester Conference Series on Public Policy, 49, 53-111.

Evans, C. L, and D. A. Marshall, 2000, "Economic Determinants of the Term Structure of Nominal Interest Rates," working paper.

Fisher, M., 1998, "A Simple Model of the Failure of the Expectations Hypthesis," working paper, Federal Reserve Bank of Atlanta.

Fisher, M., and C. Gilles, 1998, "Around and Around: The Expectations Hypothesis," Journal of Finance, 53, 1, 365-383.

Fuhrer, J. C., and G. R. Moore, 1995, "Monetary Policy Trade-Offs and the Correlation between Nominal Interest Rates and Real Output," American Economic Review, 85, 1, 219-239.

Gali, J., 1992, "How Well does the ISLM Model Fit Post War Data?" Quarterly Journal of Economics, 107, 709-738.

Hansen, L. P., and R. Jagannathan, 1991, "Implications of Security Market Data for Models of Dynamic Economies," Journal of Political Economy, 99, 225-262.

Harrison, J. M., and D. M. Kreps, 1979, "Martingales and Arbitrage in Multiperiod Securities Markets," Journal of Economic Theory, 2, 3, 381-408.

Harvey, C. R., 1988, “The Real Term Structure and Consumption Growth,” Journal of Financial Economics, 22, 2, 305-33.

Hardouvelis, G. A., 1994, "The Term Structure Spread and Future Changes in Long and Short Rates in the G7 Countries," Journal of Monetary Economics, 33, 225-283.

Knez, P. K., R. Litterman, and J. A. Scheinkman, 1994, "Explorations into Factors Explaining Money Market Returns," Journal of Finance, 49, 5, 1861-1882.

Liu, J., 1999, "Portfolio Selection in Stochastic Environments," working paper, UCLA.

Longstaff, F.A., 2000. "The Term Stucture of Very Short Term Rates: New Evidence for the Expectations Hypothesis." forthcoming in the Journal of Financial Economics.

Longstaff, F. A., and E. S. Schwartz, 1992, "Interest Rate Bolatiltiy and the Term Structure: A Two Factor General Equilibrium Model," Journal of Finance, 47, 4, 1252-82.

Newey, W. K., and K. D. West, 1987, "A Simple Positive Semi-Definite, Heteroskedasticity and Autocorrelation Consistent Covariance Matrix," Econometrica, 55, 703-8.

Pearson, N., and T. S. Sun, 1994, "Exploiting the Conditional Density in Estimating the Term Structure: An Application to the Cox, Ingersoll and Ross Model," Journal of Finance, 54, 1279-1304.

Piazzesi, M., 2001, “An Econometric Model of the Yield Curve with Macroeconomic Jump Effects," NBER working paper 8246.

Sargent, T. J., 1979, "A Note on Maximum Likelihood Estimation of the Rational Expectations Model of the Term Structure," Journal of Monetary Economics, 35, 2, $245-74$.

Sims, C., and T. Zha, 1995, "Does Monetary Policy Generate Recessions?” working paper, Yale University.

Taylor, J. B., 1993, "Discretion versus policy rules in practice." Carnegie-Rochester Conference Series on Public Policy, 39, 195-214.

Uhlig, H., 1999, "What are the Effects of Monetary Policy ? Results from an Agnostic Identification Procedure," working paper, Tilburg University.

Vasicek, O., 1977, “An Equilibrium Characterization of the Term Structure,” Journal of Financial Economics, 5, 177-188. 
Table 1: Summary Statistics of Data

\begin{tabular}{ccccc|ccc}
\multicolumn{7}{c}{ Central Moments } & \multicolumn{3}{c}{ Autocorrelations } \\
& mean & stdev & skew & kurt & lag 1 & lag 2 & lag 3 \\
\hline $1 \mathrm{mth}$ & 5.1316 & 2.7399 & 1.0756 & 4.6425 & 0.9716 & 0.9453 & 0.9323 \\
$3 \mathrm{mth}$ & 5.4815 & 2.8550 & 1.0704 & 4.5543 & 0.9815 & 0.9606 & 0.9419 \\
$12 \mathrm{mth}$ & 5.8849 & 2.8445 & 0.8523 & 3.8856 & 0.9824 & 0.9626 & 0.9457 \\
$36 \mathrm{mth}$ & 6.2241 & 2.7643 & 0.7424 & 3.5090 & 0.9875 & 0.9739 & 0.9620 \\
$60 \mathrm{mth}$ & 6.4015 & 2.7264 & 0.6838 & 3.2719 & 0.9892 & 0.9782 & 0.9687 \\
\hline CPI & 3.8612 & 2.8733 & 1.2709 & 4.3655 & 0.9931 & 0.9847 & 0.9738 \\
PCOM & 0.9425 & 11.2974 & 1.0352 & 6.0273 & 0.9684 & 0.9162 & 0.8600 \\
PPI & 3.0590 & 3.6325 & 1.4436 & 4.9218 & 0.9863 & 0.9705 & 0.9521 \\
\hline HELP & 66.7517 & 22.0257 & -0.1490 & 1.8665 & 0.9944 & 0.9900 & 0.9830 \\
EMPLOY & 1.6594 & 1.5282 & -0.4690 & 3.2534 & 0.9378 & 0.8954 & 0.8410 \\
IP & 3.4717 & 5.3697 & -0.5578 & 3.6592 & 0.9599 & 0.8889 & 0.7972 \\
UE & 5.7344 & 1.5650 & 0.4924 & 3.2413 & 0.9906 & 0.9777 & 0.9595
\end{tabular}

The 1, 3, 12, 36 and 60 month yields are annual zero coupon bond yields from the Fama-Bliss CRSP bond files. The inflation measures CPI, PCOM and PPI refer to CPI inflation, spot market commodity price inflation, and PPI (Finished Goods) inflation respectively. We calculate the inflation measure at time $t$ using $\log \left(P_{t} / P_{t-12}\right)$ where $P_{t}$ is the inflation index. The real activity measures HELP, EMPLOY, IP and UE refer to the Index of Help Wanted Advertising in Newspapers, the growth rate of employment, the growth rate in industrial production and the unemployment rate respectively. The growth rate in employment and industrial production are calculated using $\log \left(I_{t} / I_{t-12}\right)$ where $I_{t}$ is the employment or industrial production index. For the macro variables, the sample period is 1952:01 to 2000:12. For the bond yields, the sample period is 1952:06 to 2000:12. 


\section{Table 2: Principal Component Analysis}

\begin{tabular}{crrrc}
\multicolumn{5}{c}{ Principal Components: Inflation } \\
& \multicolumn{1}{c}{ 1st } & \multicolumn{1}{c}{ 2nd } & \multicolumn{1}{c}{ 3rd } & Foadtor \\
& Loading \\
\hline CPI & -0.6343 & -0.3674 & 0.6802 & -0.9286 \\
PCOM & -0.4031 & 0.9080 & 0.1145 & -0.5901 \\
PPI & -0.6597 & -0.2015 & -0.7240 & -0.9657 \\
\% variance & & & & \\
explained & 0.7143 & 0.9775 & 1.0000 & \\
\hline
\end{tabular}

Principal Components: Real Activity

\begin{tabular}{crrrrr} 
& \multicolumn{1}{c}{ 1st } & \multicolumn{1}{c}{ 2nd } & \multicolumn{1}{c}{ 3rd } & \multicolumn{1}{c}{ 4th } & \multicolumn{1}{c}{ Foading } \\
\hline HELP & -0.3204 & -0.7365 & -0.5300 & 0.2719 & -0.4622 \\
UE & 0.3597 & -0.6283 & 0.6871 & 0.0612 & 0.5188 \\
EMPLOY & -0.6330 & -0.1648 & 0.2444 & -0.7158 & -0.9131 \\
IP & -0.6060 & 0.1886 & 0.4327 & 0.6403 & -0.8742 \\
\% variance & & & & & \\
explained & 0.5202 & 0.7946 & 0.9518 & 1.0000 & \\
\hline
\end{tabular}

We take the three (four) macro variables representing inflation (real activity) and normalize them to unit variance. Then the normalized data $Z_{t}$ has the following 1 factor model:

$$
Z_{t}=C f_{t}^{o}+\epsilon_{t}
$$

where $C$ is the factor loading vector, $\mathrm{E}\left(f_{t}^{o}\right)=0, \operatorname{cov}\left(f_{t}^{o}\right)=I, \mathrm{E}\left(\epsilon_{t}\right)=0$, and $\operatorname{cov}\left(\epsilon_{t}\right)=\Gamma$, where $\Gamma$ is a diagonal matrix. The columns titled "principal components" list the principal components corresponding to the first to smallest eigenvalue. The \% variance explained for the $n$th principal component gives the cumulative proportion of the variance explained by the first up to the $n$th eigenvalue. IP refers to the growth in industrial production, CPI to CPI inflation, PCOM to commodity price inflation and PPI to PPI inflation, HELP refers to the Index of Help Wanted Advertising in Newspapers, UE to the unemployment rate, EMPLOY to the growth in employment. The sample period is 1952:01 to 2000:12 


\section{Table 3: Selected Correlations}

$\begin{array}{ccccc} & \text { CPI } & \text { PCOM } & \text { PPI } & \\ \text { Inflation } & 0.9286 & 0.5901 & 0.9657 & \\ & & & & \\ \text { Real Activity } & \text { HELP } & \text { UE } & \text { EMPLOY } & \text { IP } \\ & 0.4622 & -0.5188 & 0.9131 & 0.8742 \\ & & & & \\ & \text { Real } & & \\ \text { Real Activity } & 0.0017 & \text { Activity } & 1 \mathrm{mth} & 12 \mathrm{mth} \\ 1 \text { mth } & 0.6666 & 0.0627 & & \\ 12 \text { mth } & 0.6484 & 0.0510 & 0.9771 & \\ 60 \text { mth } & 0.5614 & -0.0270 & 0.9191 & 0.9639\end{array}$

The table reports selected correlations for the inflation factor extracted from the first principal component of PCI, PCOM and PPI, the real activity factor extracted from the first principal component of HELP, UE, EMPLOY and IP, and the 1, 12 and 60 month bond yields, which are used in the estimation. IP refers to the growth in industrial production, CPI to CPI inflation, PCOM to commodity price inflation, PPI to PPI inflation, HELP refers to the Index of Help Wanted Advertising in Newspapers, UE to the unemployment rate, EMPLOY to the growth in employment. The sample period is 1952:06 to 2000:12. 
Table 4: The Dependence of the Short Rate on Macro Variables

Panel A: $y_{t}^{1}$ on Constant, Inflation and Real activity

$\begin{array}{ccccc}\text { Coeff } & \text { Inflation } & \text { Real Activity } & \text { Constant } & \text { Adj } R^{2} \\ t & 0.0143 & 0.1535 & 0.4250 & 0.4523 \\ & (0.0070)^{*} & (0.0070)^{\dagger} & (0.007)^{\dagger} & \end{array}$

Panel B: $y_{t}^{1}$ on Constant, 12 lags of Inflation and Real activity

$\begin{array}{ccccc}\text { Coeff } & \text { Inflation } & \text { Real activity } & \text { Constant } & \text { Adj } R^{2} \\ t & 0.0037 & 0.0398 & 0.4296 & 0.5337 \\ & (0.0534) & (0.0065)^{\dagger} & (0.0306)^{\dagger} & \\ t-1 & 0.0659 & 0.0150 & & \\ & (0.0828) & (0.0452) & & \\ t-2 & -0.0435 & 0.0105 & \\ & (0.0830) & (0.0450) & \\ t-3 & 0.0062 & -0.0054 & \\ & (0.0833) & (0.0444) & \\ t-4 & 0.0233 & -0.0172 & \\ & (0.0828) & (0.0441) & \\ t-5 & -0.0088 & 0.0145 & \\ & (0.0825) & (0.0442) & \\ t-6 & -0.0245 & -0.0213 & \\ & (0.0825) & (0.0438) & \\ t-7 & 0.0175 & 0.0062 & \\ & (0.0821) & (0.0435) & \\ t-8 & 0.0080 & 0.0196 & \\ & (0.0825) & (0.0438) & \\ t-9 & -0.0049 & 0.0121 & \\ t-10 & (0.0821) & (0.0441) & \\ & -0.0079 & 0.0005 & \\ & (0.0820) & (0.0439) & \end{array}$

In Panel A we regress the 1 month yield $y_{t}^{1}$ on a constant, the inflation factor and the real activity factor. In Panel B we regress $y_{t}^{1}$ on a constant, inflation, real activity and 11 lags of inflation and real activity. We report OLS standard errors in parenthesis. Standard errors significant at the 5\% (1\%) level are denoted ${ }^{*}\left({ }^{\dagger}\right)$. Sample period is 1952:01 to 2000:12. 


\section{Table 5: Yields-Only Model Estimates}

\begin{tabular}{ccc}
\multicolumn{3}{c}{ Companion Form $\Phi$} \\
0.9924 & 0.0000 & 0.0000 \\
$(0.0039)$ & & \\
0.0000 & 0.9548 & 0.0000 \\
& $(0.0062)$ & \\
0.0000 & -0.0021 & 0.7646 \\
& $(0.0001)$ & $(0.0210)$
\end{tabular}

Short Rate Parameters $\delta_{1}(\times 100)$

Unobs 1 Unobs 2 Unobs 3

$\begin{array}{lll}0.0136 & -0.0451 & 0.0237\end{array}$

$\begin{array}{lll}(0.0020) & (0.0005) \quad(0.0015)\end{array}$

Prices of Risk $\lambda_{0}$ and $\lambda_{1}$

\begin{tabular}{ccccc} 
& & \multicolumn{3}{c}{$\lambda_{1}$ matrix } \\
& $\lambda_{0}$ & Unobs 1 & Unobs 2 & Unobs 3 \\
Unobs 1 & -0.0033 & -0.0069 & 0.0000 & 0.0000 \\
& $(0.0004)$ & $(0.0040)$ & & \\
Unobs 2 & 0.0000 & 0.0445 & 0.0000 & -0.2585 \\
& & $(0.0050)$ & & $(0.0197)$ \\
Unobs 3 & 0.0000 & -0.0049 & 0.0000 & 0.0241 \\
& & $(0.0090)$ & & $(0.0026)$
\end{tabular}

Measurement Error $(\times 100)$

3 month 36 month

$0.0203 \quad 0.0090$

$(0.0003) \quad(0.0002)$

The table reports parameter estimates and standard errors in parenthesis for the 3-factor Yields-Only model $X_{t}=\Phi X_{t-1}+\epsilon_{t}$, with $\epsilon_{t} \sim N(0, I), \Phi$ lower triangular and the short rate equation given by $r_{t}=\delta_{0}+\delta_{1}^{\prime} X_{t}$. All factors $X_{t} \equiv f_{t}^{u}$ are unobservable. The coefficient $\delta_{0}$ is set to the sample unconditional mean of the short rate, $0.0513 / 12$. The prices of risk $\lambda_{t}$ are given by $\lambda_{t}=\lambda_{0}+\lambda_{1} X_{t}$. The system is first estimated with $\lambda_{0}=0$ and $\lambda_{1}$ unconstrained. In a second estimation, the insignificant coefficients in $\lambda_{1}$ are set to zero. The sample period is 1952:06 to 2000:12. 


\section{Table 6: Macro Model Estimates}

$\begin{array}{ccc}\text { Companion Form } \Phi \text { for Latent Factors } \\ 0.9915 & 0.0000 & 0.0000 \\ (0.0042) & & \\ 0.0000 & 0.9392 & 0.0000 \\ & (0.0122) & \\ 0.0000 & 0.0125 & 0.7728 \\ & (0.0146) & (0.0217)\end{array}$

Short Rate Parameters $\delta_{1}$ for Latent Factors $(\times 100)$

$\begin{array}{ccc}\text { Unobs 1 } & \text { Unobs 2 } & \text { Unobs } 3 \\ 0.0138 & -0.0487 & 0.0190 \\ (0.0021) & (0.0007) & (0.0022)\end{array}$

Prices of Risk $\lambda_{0}$ and $\lambda_{1}$

\begin{tabular}{ccccccc} 
& $\lambda_{0}$ & \multicolumn{5}{c}{$\lambda_{1}$ matrix } \\
& & Real & & \\
Inflation & Activity & Unobs 1 & Unobs 2 & Unobs 3 \\
Inflation & 0.0000 & -0.4263 & 0.1616 & 0.0000 & 0.0000 & 0.0000 \\
& & $(0.1331)$ & $(0.0146)$ & & & \\
Real Activity & 0.0000 & 1.9322 & -0.1015 & 0.0000 & 0.0000 & 0.0000 \\
& & $(0.3893)$ & $(0.0329)$ & & & \\
Unobs 1 & -0.0039 & 0.0000 & 0.0000 & -0.0047 & 0.0000 & 0.0000 \\
& $(0.0003)$ & & & $(0.0043)$ & & \\
Unobs 2 & 0.0000 & 0.0000 & 0.0000 & 0.0459 & 0.0000 & -0.2921 \\
& & & & $(0.0055)$ & & $(0.0205)$ \\
Unobs 3 & 0.0000 & 0.0000 & 0.0000 & -0.0035 & 0.0000 & 0.0200 \\
& & & & $(0.0001)$ & & $(0.0028)$
\end{tabular}

$\begin{array}{cc}\text { Measurement } & \text { Error }(\times 100) \\ 3 \text { month } & 36 \text { month } \\ 0.0207 & 0.0091 \\ (0.0003) & (0.0002)\end{array}$

The table reports parameter estimates and standard errors in parenthesis for the Macro model with the short rate equation specified with only current inflation and current real activity, as reported in Panel A of Table 4. The short rate equation is given by $r_{t}=\delta_{0}+\delta_{1}^{\prime} X_{t}$, where $\delta_{1}$ only picks up current inflation, current real activity and the latent factors. The dynamics of inflation and real activity are given by a 12 lag VAR (not reported). The model is $X_{t}=\Phi X_{t-1}+\epsilon_{t}$, with $\epsilon_{t} \sim N(0, I) . X_{t}$ contains 12 lags of inflation and real activity and three latent variables, which are independent at all lags to the macro variables. In a pre-estimation we find the inflation and real activity VAR(12), and the coefficients on inflation and real activity in the short rate equation. The coefficient $\delta_{0}$ is set to the sample unconditional mean of the short rate, $0.0513 / 12$. We first estimate the latent factor parameters and the prices of risk $\lambda_{t}=\lambda_{0}+\lambda_{1} X_{t}$, restricting $\lambda_{1}$ to be block diagonal and using the same form of the prices of risk for the latent factors as the Yields-Only estimation in Table 5. In a second estimation, the insignificant coefficients in $\lambda_{0}$ and $\lambda_{1}$ are set to zero. The sample period is 1952:06 to 2000:12. 


\section{Table 7: Macro Lag Model Estimates}

$\begin{array}{ccc}\text { Companion Form } \Phi \text { for Latent Factors } \\ 0.9922 & 0.0000 & 0.0000 \\ (0.0039) & & \\ 0.0000 & 0.9431 & 0.0000 \\ & (0.0118) & \\ 0.0000 & -0.0189 & 0.8210 \\ & (0.0135) & (0.0216)\end{array}$

Short Rate Parameters $\delta_{1}$ for Latent Factors $(\times 100)$

$\begin{array}{ccc}\text { Unobs 1 } & \text { Unobs 2 } & \text { Unobs } 3 \\ 0.0130 & -0.0438 & 0.0256 \\ (0.0020) & (0.0010) & (0.0025)\end{array}$

Prices of Risk $\lambda_{0}$ and $\lambda_{1}$

\begin{tabular}{ccccccc} 
& $\lambda_{0}$ & \multicolumn{5}{c}{$\lambda_{1}$ matrix } \\
& & Real & & \\
Inflation & Activity & Unobs 1 & Unobs 2 & Unobs 3 \\
Real Activity & 0.0000 & $\begin{array}{l}-0.8442 \\
-0.0017\end{array}$ & 0.0000 & 0.0000 & 0.0000 \\
& 0.0000 & $\begin{array}{c}(0.2397) \\
(1.1209\end{array}$ & $0.0582)$ & & & \\
Unobs 1 & -0.0050 & $0.1375)$ & $(0.0275)$ & 0.0000 & 0.0000 & 0.0000 \\
& $(0.0003)$ & & 0.0000 & -0.0048 & 0.0000 & 0.0000 \\
Unobs 2 & 0.0000 & 0.0000 & 0.0000 & 0.0483 & 0.0000 & -0.2713 \\
& & & & $(0.0068)$ & & $(0.0195)$ \\
Unobs 3 & 0.0000 & 0.0000 & 0.0000 & -0.0248 & 0.0000 & 0.1624 \\
& & & & $(0.0078)$ & & $(0.0292)$
\end{tabular}

$\begin{array}{cc}\text { Measurement } & \text { Error }(\times 100) \\ 3 \text { month } & 36 \text { month } \\ 0.0251 & 0.0107 \\ (0.0005) & (0.0003)\end{array}$

The table reports parameter estimates and standard errors in parenthesis for the Macro Lag model with the short rate equation specified with 12 lags of inflation and current real activity, as reported in Panel B of Table 4. The short rate equation is given by $r_{t}=\delta_{0}+\delta_{1}^{\prime} X_{t}$, where $\delta_{1}$ only picks up 12 lags of inflation and real activity and the latent factors. The dynamics of inflation and real activity are given by a 12 lag VAR (not reported). The model is $X_{t}=\Phi X_{t-1}+\epsilon_{t}$, with $\epsilon_{t} \sim N(0, I) . X_{t}$ contains 12 lags of inflation and real activity and three latent variables, which are independent at all lags to the macro variables. In a pre-estimation we find the inflation and real activity VAR(12), and the coefficients on inflation and real activity in the short rate equation. The coefficient $\delta_{0}$ is set to the sample unconditional mean of the short rate, 0.0513/12. We first estimate the latent factor parameters and the prices of risk $\lambda_{t}=\lambda_{0}+\lambda_{1} X_{t}$, restricting $\lambda_{1}$ to be block diagonal and not picking up any lagged variables. We us the same form of the prices of risk for the latent factors as the Yields-Only estimation in Table 5. In a second estimation, the insignificant coefficients in $\lambda_{0}$ and $\lambda_{1}$ are set to zero. The sample period is 1952:06 to 2000:12. 
Table 8: Proportion of Variance Explained by Macro Factors in the Macro Model

\begin{tabular}{lcccc} 
& \multicolumn{4}{c}{ Horizon $h$} \\
& $1 \mathrm{mth}$ & $12 \mathrm{mth}$ & $60 \mathrm{mth}$ & $\infty$ \\
short end & $50 \%$ & $78 \%$ & $85 \%$ & $83 \%$ \\
middle & $67 \%$ & $79 \%$ & $78 \%$ & $73 \%$ \\
long end & $61 \%$ & $63 \%$ & $48 \%$ & $38 \%$
\end{tabular}

We list the contribution of the macro factors to the $h$-step ahead forecast variance of the 1 month yield (short end), 12 month yield (middle) and 60 month yield (long end). These are the variance decompositions from the Macro model outlined in more detail in Table 9. 
Table 9: Variance Decompositions

\begin{tabular}{|c|c|c|c|c|c|c|}
\hline & \multicolumn{3}{|c|}{ Macro Factors } & \multicolumn{3}{|c|}{ Latent Factors } \\
\hline & $h$ & Inflation & $\begin{array}{c}\text { Real } \\
\text { Activity }\end{array}$ & Unobs 1 & Unobs 2 & Unobs 3 \\
\hline \multicolumn{7}{|c|}{1 month yield } \\
\hline & 1 & & & 0.1381 & 0.3303 & 0.5314 \\
\hline \multirow{3}{*}{ Yields-Only } & 12 & & & 0.3081 & 0.4342 & 0.2577 \\
\hline & 60 & & & 0.5579 & 0.3116 & 0.1305 \\
\hline & $\infty$ & & & 0.6771 & 0.2279 & 0.0950 \\
\hline \multirow{4}{*}{ Macro } & 1 & 0.4887 & 0.0074 & 0.0328 & 0.4088 & 0.0622 \\
\hline & 12 & 0.6860 & 0.0946 & 0.0251 & 0.1836 & 0.0108 \\
\hline & 60 & 0.7139 & 0.1372 & 0.0390 & 0.1050 & 0.0048 \\
\hline & $\infty$ & 0.6985 & 0.1343 & 0.0597 & 0.1027 & 0.0047 \\
\hline \multirow{4}{*}{$\begin{array}{l}\text { Macro } \\
\text { with Lags }\end{array}$} & 1 & 0.0005 & 0.1081 & 0.0549 & 0.6235 & 0.2130 \\
\hline & 12 & 0.2242 & 0.3478 & 0.0446 & 0.3357 & 0.0477 \\
\hline & 60 & 0.6885 & 0.1805 & 0.0315 & 0.0900 & 0.0095 \\
\hline & $\infty$ & 0.6749 & 0.1768 & 0.0507 & 0.0882 & 0.0093 \\
\hline \multicolumn{7}{|c|}{12 month yield } \\
\hline & 1 & & & 0.5972 & 0.3517 & 0.0511 \\
\hline \multirow{3}{*}{ Yields-Only } & 12 & & & 0.7116 & 0.2752 & 0.0132 \\
\hline & 60 & & & 0.8594 & 0.1361 & 0.0045 \\
\hline & $\infty$ & & & 0.9103 & 0.0869 & 0.0028 \\
\hline \multirow{4}{*}{ Macro } & 1 & 0.6343 & 0.0332 & 0.0733 & 0.2112 & 0.0480 \\
\hline & 12 & 0.7066 & 0.0848 & 0.0709 & 0.1272 & 0.0105 \\
\hline & 60 & 0.6615 & 0.1208 & 0.1271 & 0.0851 & 0.0054 \\
\hline & $\infty$ & 0.6173 & 0.1128 & 0.1854 & 0.0794 & 0.0051 \\
\hline \multirow{4}{*}{$\begin{array}{l}\text { Macro } \\
\text { with Lags }\end{array}$} & 1 & 0.0166 & 0.2107 & 0.2114 & 0.4659 & 0.0955 \\
\hline & 12 & 0.3268 & 0.1895 & 0.2001 & 0.2588 & 0.0249 \\
\hline & 60 & 0.5879 & 0.1249 & 0.1905 & 0.0899 & 0.0067 \\
\hline & $\infty$ & 0.5237 & 0.1113 & 0.2790 & 0.0801 & 0.0060 \\
\hline \multicolumn{7}{|c|}{60 month yield } \\
\hline & 1 & & & 0.7507 & 0.1963 & 0.0530 \\
\hline \multirow[t]{3}{*}{ Yields-Only } & 12 & & & 0.8443 & 0.1427 & 0.0130 \\
\hline & 60 & & & 0.9319 & 0.0641 & 0.0040 \\
\hline & $\infty$ & & & 0.9578 & 0.0397 & 0.0025 \\
\hline \multirow{4}{*}{ Macro } & 1 & 0.5950 & 0.0170 & 0.2756 & 0.0804 & 0.0319 \\
\hline & 12 & 0.5690 & 0.0615 & 0.3054 & 0.0561 & 0.0080 \\
\hline & 60 & 0.4027 & 0.0755 & 0.4848 & 0.0333 & 0.0037 \\
\hline & $\infty$ & 0.3164 & 0.0593 & 0.5953 & 0.0262 & 0.0029 \\
\hline \multirow{4}{*}{$\begin{array}{l}\text { Macro } \\
\text { with Lags }\end{array}$} & 1 & 0.0021 & 0.0199 & 0.8060 & 0.1184 & 0.0535 \\
\hline & 12 & 0.0597 & 0.0170 & 0.8376 & 0.0703 & 0.0153 \\
\hline & 60 & 0.0906 & 0.0169 & 0.8619 & 0.0262 & 0.0045 \\
\hline & $\infty$ & 0.0582 & 0.0108 & 0.9112 & 0.0168 & 0.0029 \\
\hline
\end{tabular}

The table lists the contribution of factor $i$ to the $h$-step ahead forecast of the 1 month yield. To interpret the top row, for the Yields-Only model, $13.81 \%$ of the 1-step ahead forecast variance is explained by the first unobserved factor, $33.03 \%$ by the second unobserved factor and $53.14 \%$ by the third unobserved factor. The Yields-Only model only has three latent factors. The macro models have inflation, real activity and three latent factors. The Macro model has no lags of inflation and real activity in the short rate equation, while the Macro with Lags model does. 


\section{Table 10: Comparison of Yields-Only and Macro Factors}

\begin{tabular}{|c|c|c|c|c|c|c|}
\hline \multirow[b]{2}{*}{$\begin{array}{c}\text { Dependent } \\
\text { Variable }\end{array}$} & \multicolumn{5}{|c|}{ Independent Variables } & \multirow[b]{2}{*}{$\operatorname{Adj} R^{2}$} \\
\hline & Inflation & $\begin{array}{c}\text { Real } \\
\text { Activity }\end{array}$ & Unobs 1 & Unobs 2 & Unobs 3 & \\
\hline \multicolumn{7}{|c|}{ Panel A: Regressions on Macro Factors } \\
\hline $\begin{array}{l}\text { Unobs } 1 \\
\text { "level" }\end{array}$ & $\begin{array}{c}0.4625 \\
(0.0735)\end{array}$ & $\begin{array}{l}-0.0726 \\
(0.0860)\end{array}$ & & & & 0.2180 \\
\hline $\begin{array}{l}\text { Unobs } 2 \\
\text { "spread" }\end{array}$ & $\begin{array}{l}-0.6707 \\
(0.0716)\end{array}$ & $\begin{array}{c}-0.1890 \\
(0.0611)\end{array}$ & & & & 0.4902 \\
\hline $\begin{array}{l}\text { Unobs } 3 \\
\text { "curvature" }\end{array}$ & $\begin{array}{c}0.0498 \\
(0.0629)\end{array}$ & $\begin{array}{c}-0.1794 \\
(0.0714)\end{array}$ & & & & 0.0343 \\
\hline
\end{tabular}

Panel B: Regressions on Factors from Macro Model

$\begin{array}{lcccccc}\text { Unobs 1 } & 0.1118 & 0.0307 & 0.9507 & -0.0174 & 0.0038 & 0.9971 \\ & (0.0054) & (0.0056) & (0.0055) & (0.0056) & (0.0047) & \\ \text { Unobs 2 } & -0.9364 & -0.1026 & 0.0199 & 0.7624 & 0.0279 & 0.9981 \\ & (0.0037) & (0.0037) & (0.0042) & (0.0032) & (0.0029) & \\ \text { Unobs 3 } & 0.0427 & -0.1238 & 0.1656 & -0.1455 & 0.9071 & 0.9256 \\ & (0.0262) & (0.0260) & (0.0289) & (0.0241) & (0.0233) & \end{array}$

Panel C: Regressions on Factors from Macro Lag Model

$\begin{array}{lcccccc}\text { Unobs 1 } & -0.0580 & -0.0207 & 1.0248 & 0.0035 & 0.0058 & 0.9979 \\ & (0.0049) & (0.0040) & (0.0044) & (0.0047) & (0.0036) & \\ \text { Unobs 2 } & -0.7069 & -0.1132 & -0.2955 & 0.5700 & 0.1306 & 0.8715 \\ & (0.0393) & (0.0313) & (0.0356) & (0.0376) & (0.0315) & \\ \text { Unobs 3 } & 0.1112 & -0.0081 & 0.2059 & 0.0228 & 0.8119 & 0.7470 \\ & (0.0458) & (0.0386) & (0.0507) & (0.0365) & (0.0424) & \end{array}$

Regressions of the latent factors from the Yields-Only model with only latent factors (dependent variables) onto the macro factors and latent factors from the Macro and Macro Lag model (independent variables). All factors are normalized, and standard errors, produced using 3 Newey-West (1987) lags, are in parentheses. Panel A lists coefficients from a regression of the Yields-Only latent factors onto only macro factors. Panel $\mathrm{B}$ lists coefficients from a regression of Yields-Only latent factors on the macro and latent factors from the Macro model with only contemporaneous inflation and real activity in the short rate equation. Panel C lists coefficients from a regression of Yields-Only latent factors on the macro and latent factors from the Macro Lag model with contemporaneous inflation and real activity and 11 lags of inflation and real activity in the short rate equation. 


\section{Table 11: Forecast Comparisons}

\section{RMSE Criteria}

\begin{tabular}{ccccccc} 
& & Unconstrained VAR's & \multicolumn{3}{c}{ Restrictions } \\
Yield & & VAR & VAR with & Yields & Macro & Macro Lag \\
(mths) & RW & Yields Only & Macro & Only & Model & Model \\
1 & 0.3160 & 0.3905 & 0.3990 & 0.3012 & 0.2889 & 0.3906 \\
3 & 0.1523 & 0.2495 & 0.2540 & 0.1860 & 0.2167 & 0.2876 \\
12 & 0.1991 & 0.2776 & 0.2722 & 0.1914 & 0.1851 & 0.2274 \\
36 & 0.2493 & 0.3730 & 0.3644 & 0.2489 & 0.2092 & 0.2665 \\
60 & 0.2546 & 0.3793 & 0.3725 & 0.2497 & 0.2333 & 0.2530
\end{tabular}

\section{MAD Criteria}

\begin{tabular}{ccccccc} 
& & & & \multicolumn{3}{c}{ VAR's with Cross-Equation } \\
& & Unconstrained VAR's & \multicolumn{3}{c}{ Restrictions } \\
Yield & & VAR & VAR with & Yields & Macro & Macro Lag \\
(mths) & RW & Yields Only & Macro & Only & Model & Model \\
1 & 0.2252 & 0.3076 & 0.3242 & 0.2155 & 0.2039 & 0.2981 \\
3 & 0.1159 & 0.1987 & 0.2056 & 0.1442 & 0.1693 & 0.2344 \\
12 & 0.1639 & 0.2176 & 0.2204 & 0.1616 & 0.1559 & 0.1870 \\
36 & 0.1997 & 0.2991 & 0.2924 & 0.1974 & 0.1604 & 0.2111 \\
60 & 0.2054 & 0.2957 & 0.2930 & 0.2017 & 0.1883 & 0.2064
\end{tabular}

We forecast over the last 60 months (the out-sample) of our sample and record the root mean square error (RMSE) and the mean absolute deviation (MAD) of the forecast versus the actual values. Lower RMSE and MAD values denote better forecasts. Forecasts are 1-step ahead. We first estimate models on the in-sample, and update the estimations at each observation in the out-sample. RW denotes a random walk forecast, VAR Yields Only denotes a VAR(12) only with 5 yields, VAR with Macro denotes a VAR(12) fitted to the macro factors and all 5 yields, Yields-Only denotes the 3 factor latent variable model without macro variables, the Macro model has only contemporaneous inflation and real activity in the short rate equation, and the Macro Lag model has contemporaneous and 11 lags of inflation and real activity in the short rate equation. The first three of these models are thus unconstrained estimations, while the last three impose the cross-equation restrictions derived from the absence of arbitrage. 

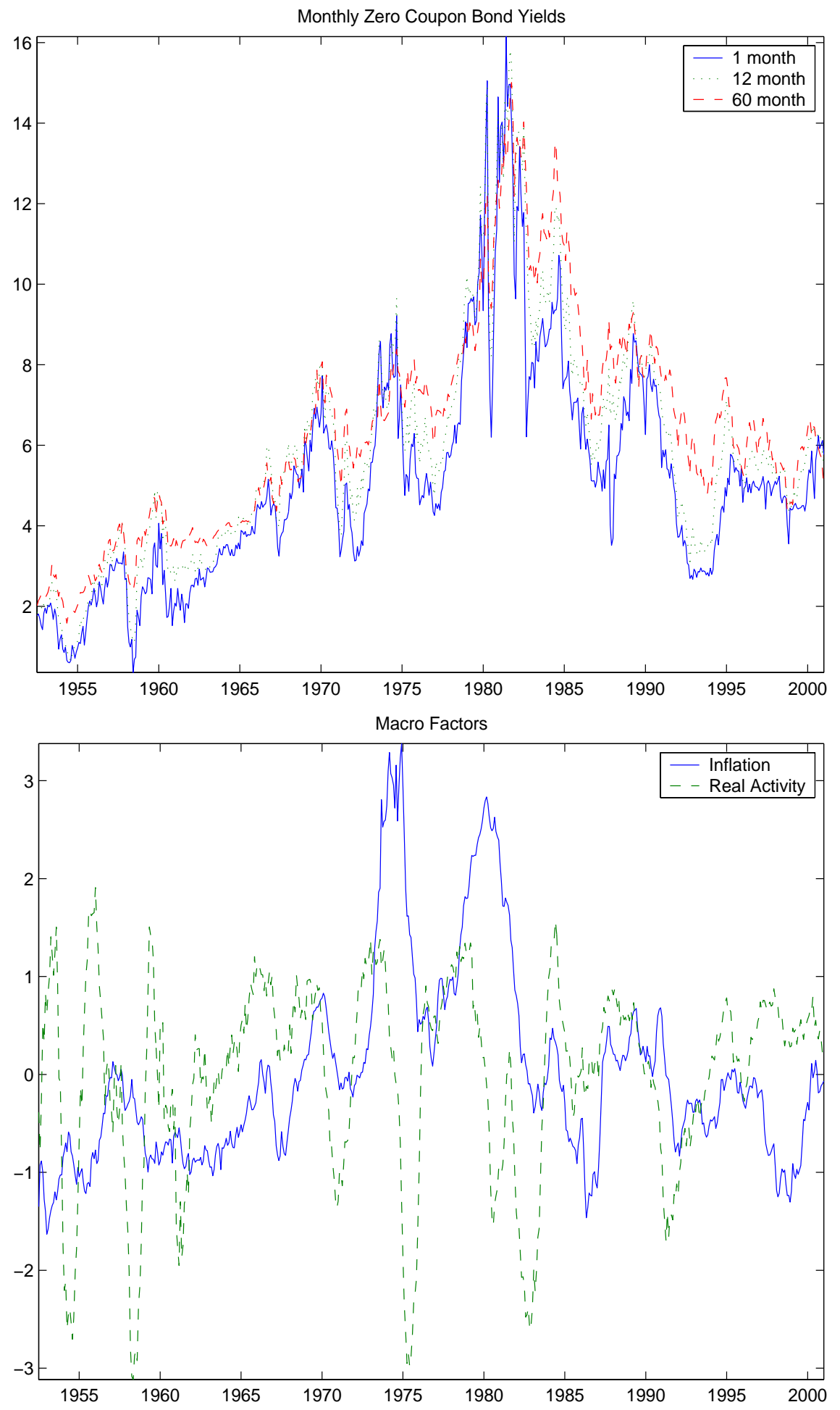

The top panel shows a plot of (annualized) monthly ZCB yields of maturity 1 month, 12 months and 60 months. The bottom panel plots the two macro factors representing inflation and real activity. The sample period is 1952:06 to 2000:12.

Figure 1: Bond Yields and Macro Principal Components 

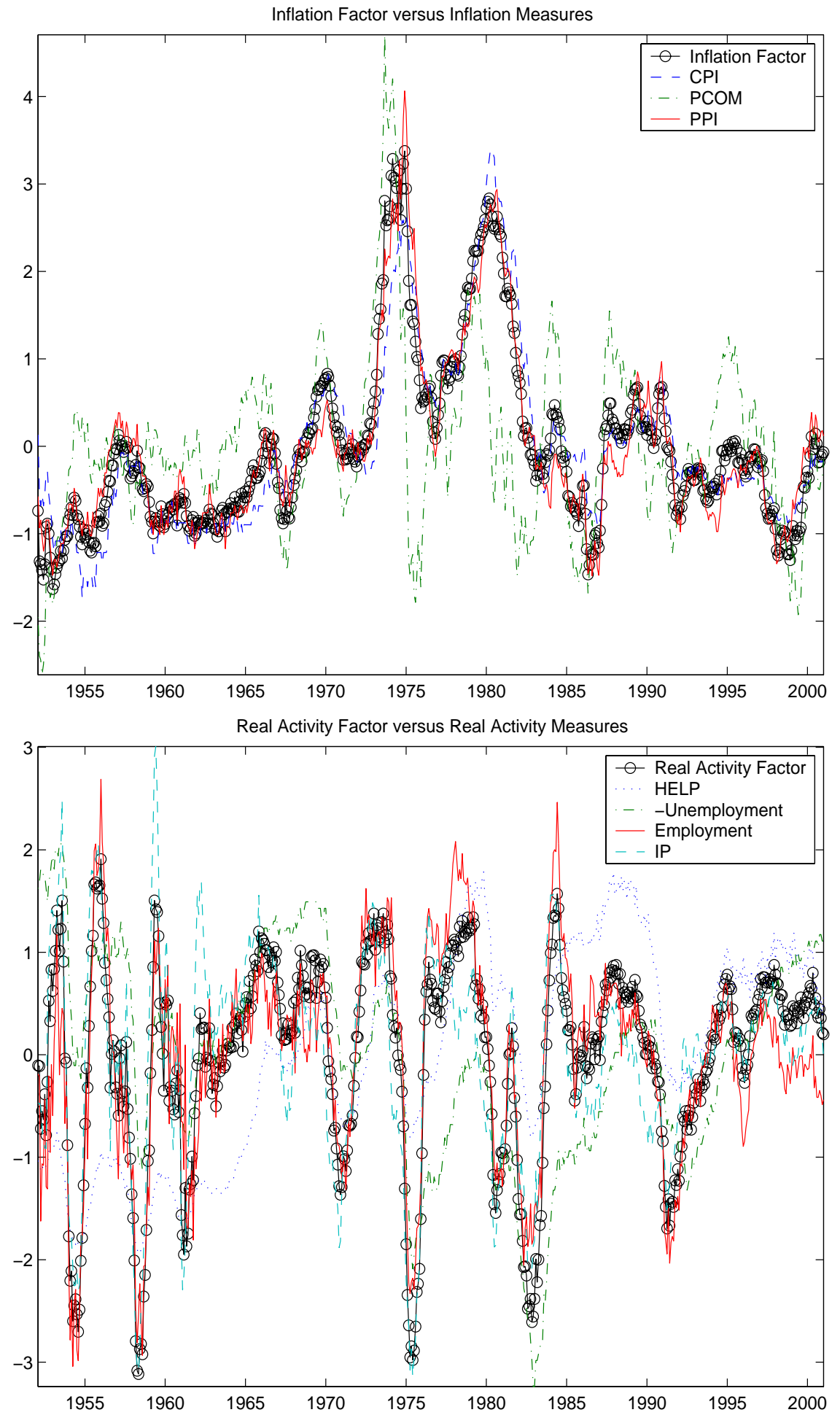

The top panel shows a plot of the inflation factor with CPI, PCOM and PPI measures of inflation. The bottom panel shows a plot of the real activity factor with HELP, the negative of unemployment, employment and IP measures of real activity. All variables are standardized to have zero mean and unit variance. The sample period is 1952:01 to 2000:12.

Figure 2: Inflation and Real Activity 

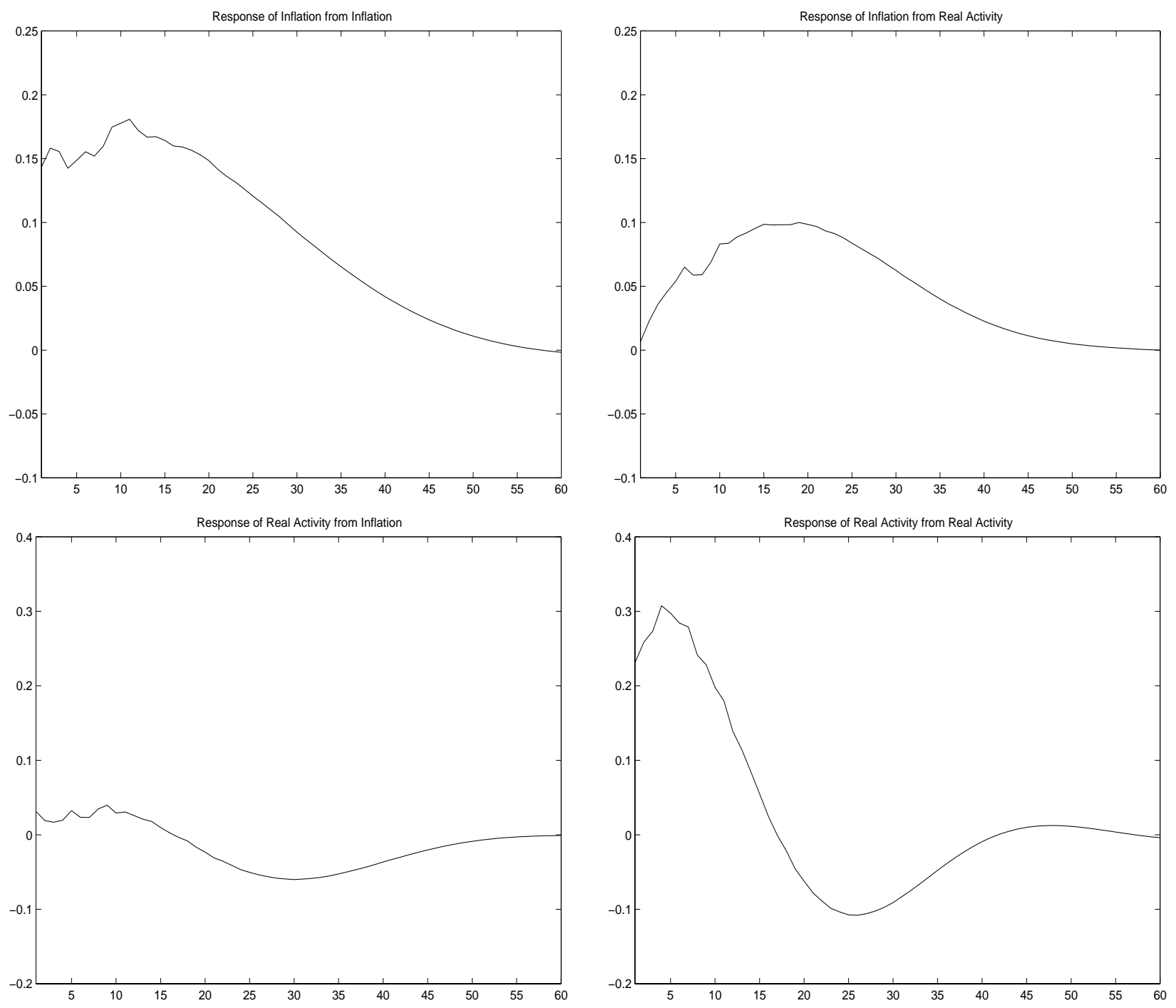

We fit a VAR(12) to the inflation and real activity macro factors. The plot shows the impulse responses to a Cholesky one standard deviation innovation to each variable. Time is in months on the $x$-axis.

Figure 3: Impulse Responses from the VAR(12) on Macro Factors 


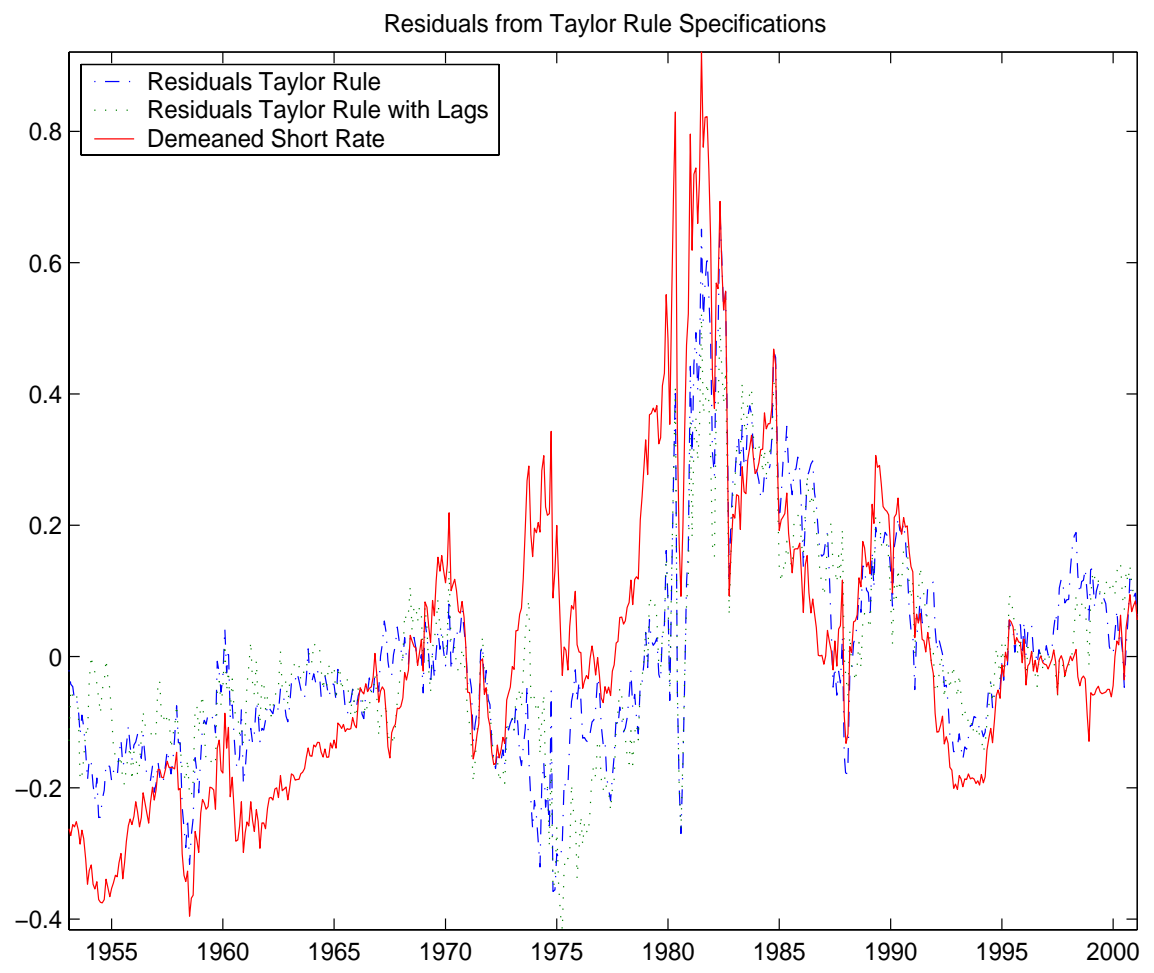

We show the residuals from the Taylor rule regressions, together with the de-meaned short rate (1 month yield). We show the residuals from the Taylor rule with no lags, which have 0.9458 autocorrelation, and the residuals from the Taylor rule with 11 lags, which have 0.9370 autocorrelation. For comparison, the autocorrelation of the short rate is 0.9716 .

Figure 4: Residuals from the Taylor Rule Regressions 

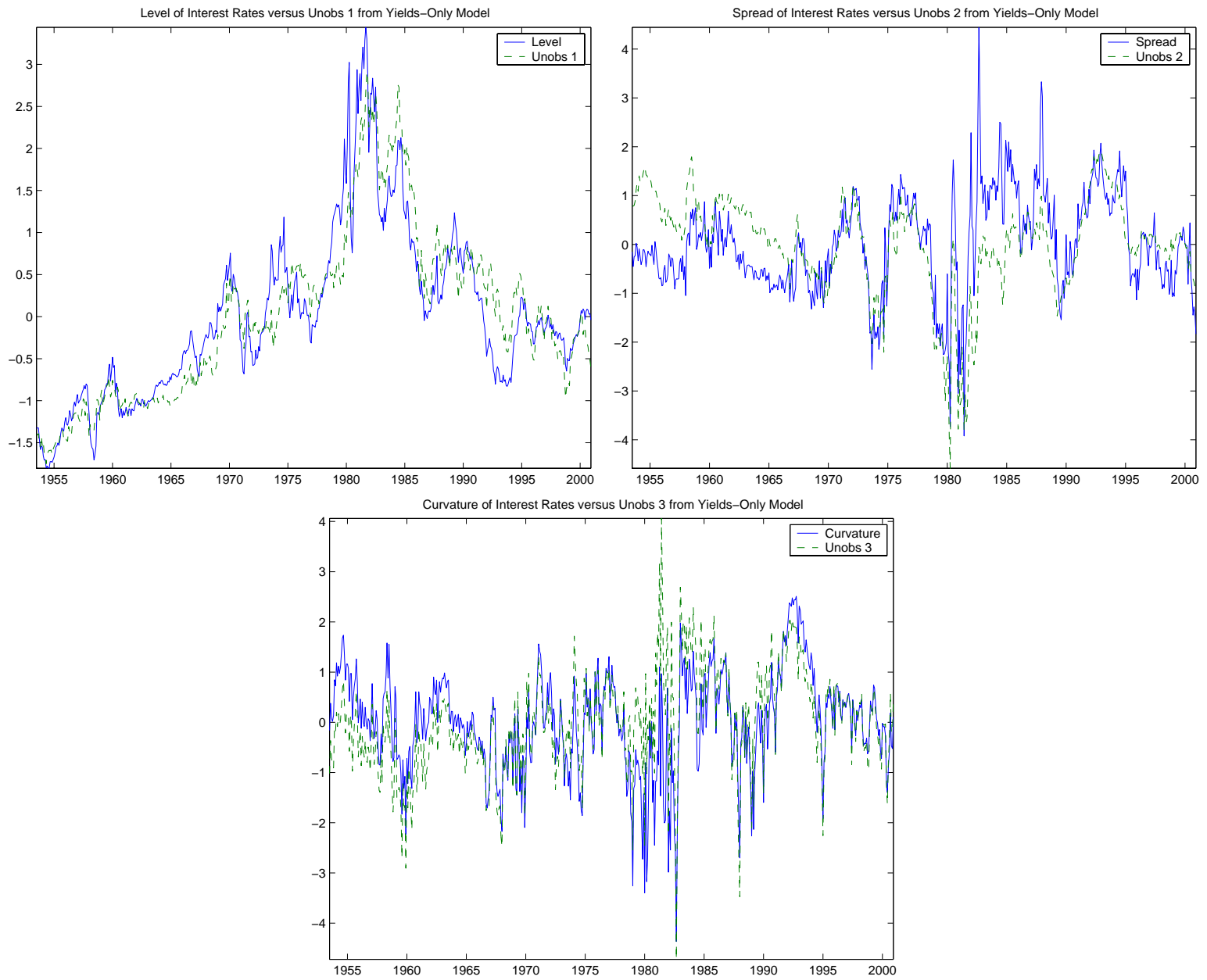

We show the unobserved yield factors from the Yields-Only model versus the level of interest rates (top left plot), spread (top right plot) and curvature of interest rates (bottom plot). All variables are normalized to have zero mean and unit variance. The level of interest rates is defined as $1 / 3\left(y_{t}^{1}+y_{t}^{12}+y_{t}^{60}\right)$ where $y_{t}^{1}, y_{t}^{12}$ and $y_{t}^{60}$ are the one-month yield, 12-month yield and 60-month yield respectively. The spread of interest rates is defined as $y_{t}^{60}-y_{t}^{1}$. The curvature of interest rates is defined as $y_{t}^{1}-2 y_{t}^{12}+y_{t}^{60}$. The correlation between the level of interest rates and Unobs 1 is $92 \%$, the correlation between the spread and Unobs 2 is 58\% and the correlation between curvature and Unobs 3 is $77 \%$.

Figure 5: Unobserved Yield Factors versus Level, Slope and Curvature 

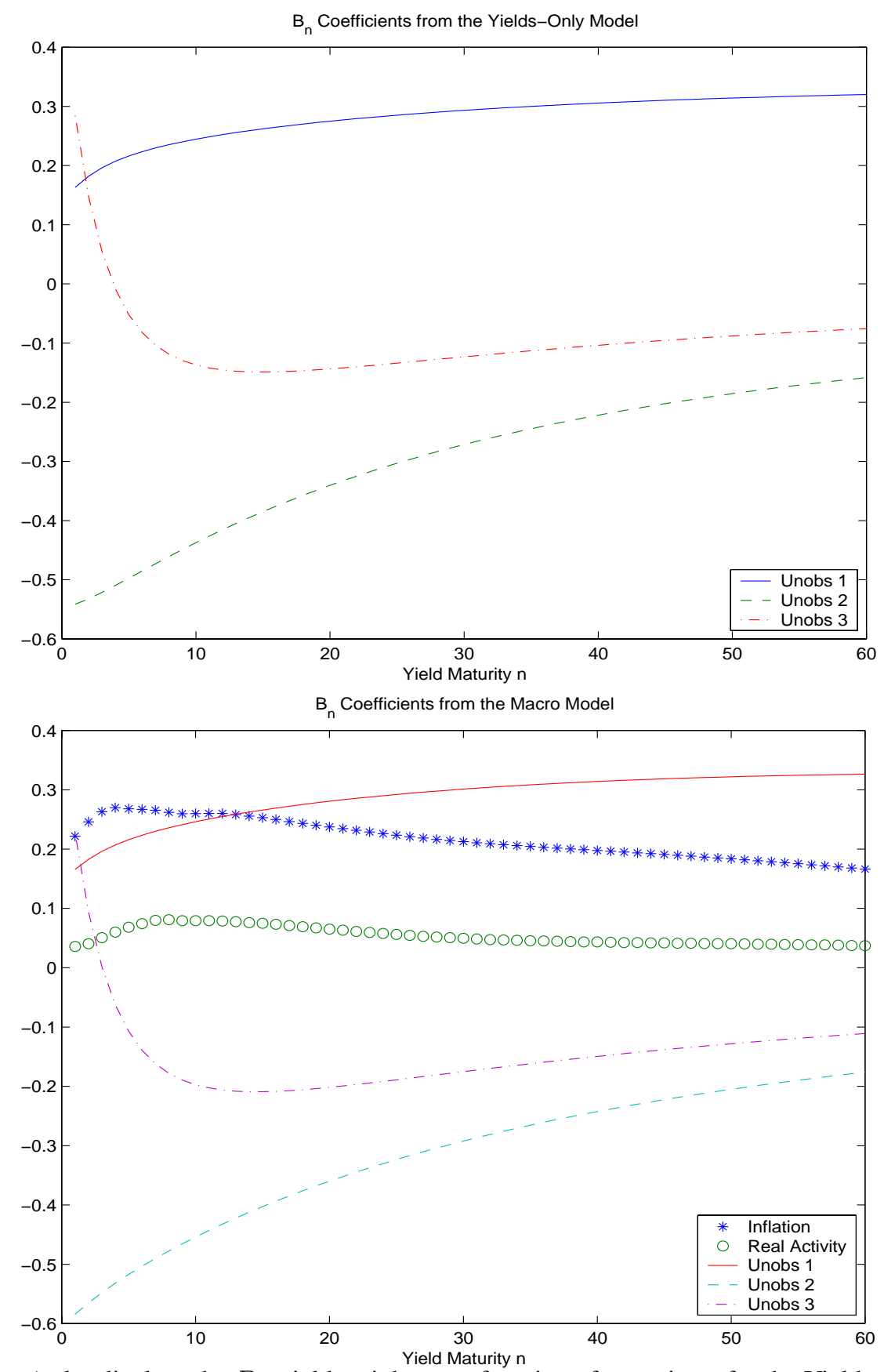

The top (bottom) plot displays the $B_{n}$ yield weights as a function of maturity $n$ for the Yields-Only (Macro) model. The weights have been scaled to correspond to one standard deviation movements in the factors and annualized by multiplying by 1200 .

Figure 6: $B_{n}$ Yield Weights for the Yields-Only and Macro Model 

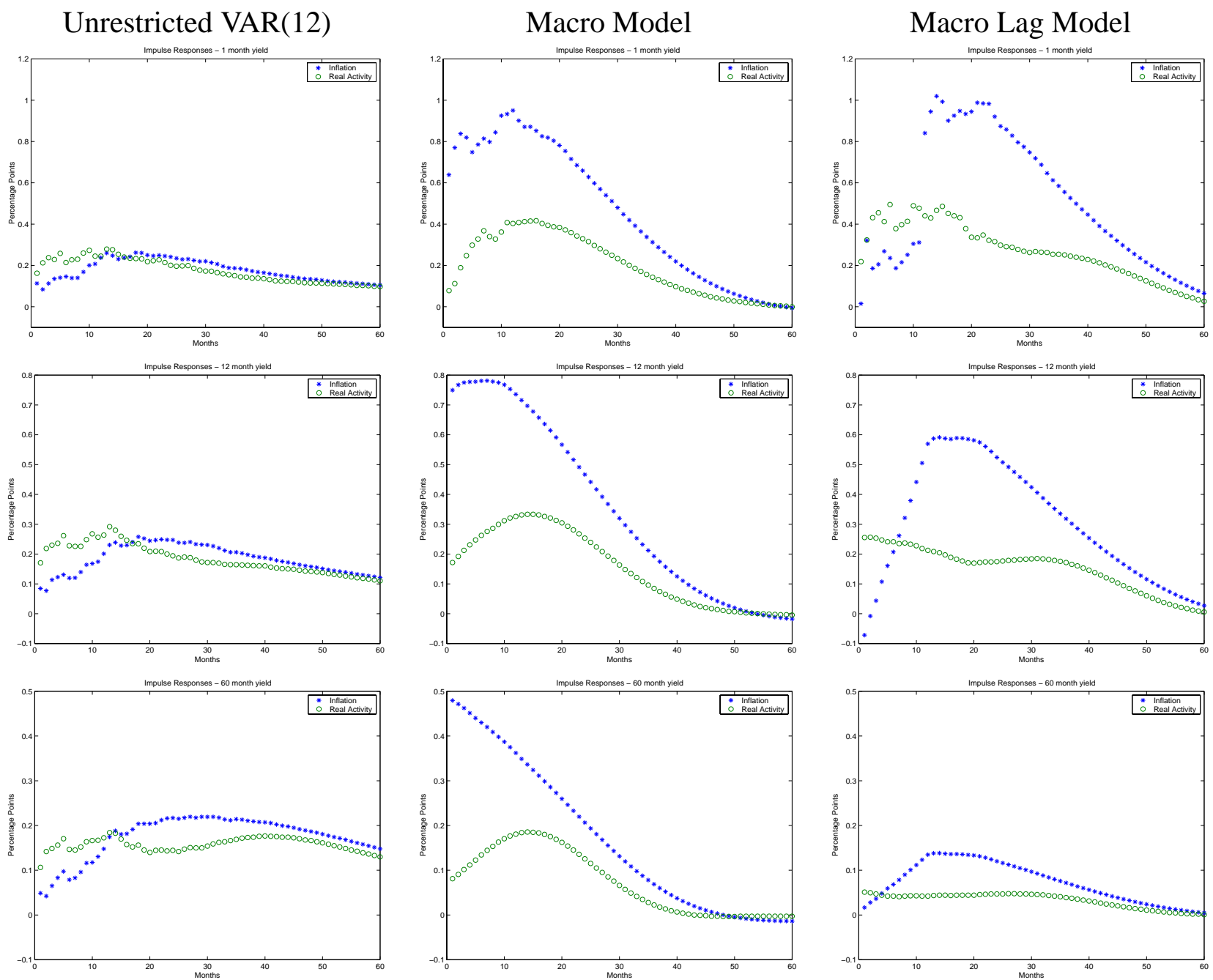

Impulse Responses (IR's) for 1 month (top row), 12 month (middle row) and 60 month (bottom row) yields. The first column presents IR's from an unrestricted VAR(12) fitted to macro variables and yields ; the middle column presents IR's from the Macro model; and the last column presents IR's from the Macro Lag model. The IR's from the latent factors are drawn as lines, while the IR's from inflation (real activity) are drawn as stars (circles). All IR's are from a one standard deviation shock.

Figure 7: Impulse Response Functions 